\title{
On the interaction of structural and semantic case
}

\author{
Dieter Wunderlich, Renate Lakämper \\ Seminar für Allgemeine Sprachwissenschaft, Heinrich-Heine-Universität Düsseldorf, \\ Universitätsstr.1, D-40225 Düsseldorf, Germany
}

\begin{abstract}
We consider two variants of morphological case: structural case (such as accusative, ergative, or dative), which is encoded by abstract case features reflecting the semantic ranking of arguments, and semantic case (such as instrumental or directional), which encodes an additional semantic relation to be licensed by the meaning of the verb. Individual verbs may be lexically marked for either structural or semantic case. We show how a correspondence-theoretic approach can successfully describe the various patterns of structural case found in German. We then discuss instances of double object where structural case and semantic case compete with each other: under certain circumstances semantic case is favored, while under other circumstances structural case is favored. We mainly consider two scenarios, described by the respective rankings of STRUCTURAL CASE (which requires all objects to be realized by a structural case) and UNIQUENESS (which restricts a structural case to occur at most once in a clause). In particular, we analyze the different options for structural vs. semantic case in the dialects of Quechua.

Keywords: Structural case; Semantic case; Abstract case; Argument linking; Double object; Ditransitive verbs; German; Quechua
\end{abstract}

\section{Introduction ${ }^{1}$}

All modern theories of grammar make a distinction between abstract case and morphological case, in some way or other. Abstract case is a condition for arguments that originates from a relational head, e.g., a verb, while morphological case is a property of the dependent NP or DP complement. Morphological case is paradigmatically organized and often subject to case concordance. The actual form of nouns, determiners and other elements of DPs may vary with respect to morphological case such as accusative, dative, or instrumental, but ultimately it is the DP as a whole that bears morphological case. A morphological case appearing on a DP must be licensed by the context of the DP.

The ideas presented in this paper were developed in collaboration with Ingrid Kaufmann, Sandra Joppen, and Barbara Stiebels. We furthermore thank Manfred Bierwisch, Miriam Butt and Paul Kiparsky for many instructive discussions, and especially Albert Ortmann for his advice regarding the final version. The Quechua data were mainly investigated by the second author. We are grateful to our informants Serafín M. Coronel-Molina (Huanca), Hernán Aguilar (Ancash), Cholo Quispe (Cuzco) and Gualberto Acebey (Potosí). The research was supported by the German Science Foundation (DFG) with a grant to the SFB 282 'Theorie des Lexikons'.

\footnotetext{
${ }^{1}$ Since the work on case competition within Optimality Theory is still in its early stages, this paper is to a large extent a programmatic one. We first have to define our notions of structural and semantic case and in what sense they serve to disambiguate argument roles. For this purpose, our concepts are introduced in a more abstract way. In section 2, we illustrate these concepts with concrete examples.
} 
We assume that morphological case appears in two variants: as structural or semantic case. Structural case (such as accusative, ergative, dative, genitive, and sometimes also partitive) reflects the ranking of arguments, while semantic case (such as, for example, instrumental, comitative, locative, directional) encodes a semantic relation between the DP and the governing head. Structural case is typical of complements; it is licensed (or generated) by abstract case. By contrast, semantic case is typical of adjuncts; it is only licensed by the meaning of the head. Thus, structural case, correlating only with the number and ranking of arguments, in a way is more economic for a language than semantic case.

Structural case forms a closed system, with dative as the most highly marked case, accusative (genitive) and ergative as less marked cases, and nominative as the unmarked (or default) case. A more marked structural case directly competes with a less marked structural case. By contrast, the potential number of semantic cases is unlimited, which can be seen, for example, from the rich system of Hungarian semantic cases, and the competition between semantic cases is always semantically determined.

Both structural and semantic case can be lexically marked. A lexically assigned structural case overrides the argument ranking; a typical example is dative for the highest argument, which crosslinguistically serves as a device to specify experiencer verbs. If a semantic case is lexically assigned by a verb, it often has some opaque reading (similar to the oblique prepositional cases in hope for, trust in, talk about), but it is also possible that an auxiliary assigns semantic case in its transparent reading in order to express a certain constructional meaning. ${ }^{2}$

Since a marked structural case always competes with a less marked structural case, it may be subject to additional semantic conditions; if these conditions are not satisfied, the less marked case appears. As shown by Mohanan (1994) and Butt (1995), the Hindi/Urdu ergative (occurring with infinitives or in the perfect, and marked with -ne) only applies to a highest argument with control properties. Therefore, transitive verbs such as bhulnaa 'forget' do not allow the ergative for the highest argument, while even agentive intransitive verbs such as cillaa 'shout', ciik $^{h}$ 'scream', naac 'dance', gaa 'sing', and $k^{h} e l$ 'play' allow the ergative (depending on whether the subject is assumed to have conscious control over the action). Similarly, the Hindi/Urdu accusative (marked with $-k o$ ) only applies to a non-highest argument which is human, specific animate, or definite inanimate. ${ }^{3}$ In all other instances the unmarked nominative appears, and since the verb agrees with the highest nominative argument it is possible for the verb to agree with either the subject or the object of a transitive verb, or with none of these (depending on the conditions under which ergative and accusative are established, see also Wunderlich 1994).

It is also possible that semantic case and structural case compete with each other, namely if the number of arguments to be realized exceeds the number of distinct structural cases. This happens with ditransitive verbs if the language has only one object case available (as in Hindi/Urdu and Quechua), and with causativized ditransitives in general because no language has three different structural object cases.

\footnotetext{
2 As in the Hindi example (27c) below.

${ }^{3}$ Urdu/Hindi exhibits an accusative-dative syncretism, which might have been enabled by the animacy/specificity split in the accusative. We deviate from the convention followed by Mohanan (1994) and Butt (1995) in that we consider - $k o$ always to be an accusative marker, which, however, can also realize the medial argument.
} 
Such an interaction of structural and semantic case can be described by a scenario in which several constraints interact. Let us assume the following constraints:

(1) a. Structural CASE: Argument roles encoded by abstract case features are realized by structural case.

b. UNIQUENESS: Each structural case is realized at most once in a clause.

c. MARK Semantics: Non-default semantic information is realized by semantic case.

d. Semantic Compatibility: A semantic case must be compatible with the meaning of the verb.

STRUCTURAL CASE states that arguments should be structurally realized, which is always the most economic way because the specific meaning of a verb need not be considered. ${ }^{4}$ UNIQUENESS is motivated by the demand of avoiding ambiguity. ${ }^{5}$ More precisely, STRUCTURAL CASE favors objects that are realized by structural case, while UNIQUENESS restricts the number of objects realized by structural case. Theoretically, there are mainly two possibilities to realize the medial argument (the 'indirect object') of a ditransitive verb if only one object case is available: either identical to the lowest argument (the 'direct object'), or by a semantic case in order to escape the restriction of UNIQUENESS. ${ }^{6}$ The first option is compatible with the ranking STRUCTURAL CASE > UNIQUENESS, while the second option is compatible with the ranking UNIQUENESS >> STRUCTURAL CASE.

In addition, in each of these scenarios semantic factors can be more important than obedience to the higher-ranked constraint. For example, if there is some need to distinguish the different roles of two objects, semantic case can appear as last resort under the first option. Conversely, if a particular semantic case conflicts with the meaning of the verb, structural case can appear as last resort under

\footnotetext{
${ }^{4}$ Two senses of 'economy' play a role here: (i) It is more economic to check a case in terms of structural features than in terms of the meaning of the verb. (ii) NPs bearing structural case can undergo further structural processes (such as promotion to 'subject'), whereas NPs bearing semantic case usually are blocked from these processes. Note further that STRUCTURAL CASE is reformulated as a MAX constraint in the later sections.

${ }^{5}$ One reviewer suggested to us that UNIQUENESS should be restricted to individual arguments in order to allow the same case on both the predicative noun and the subject. Cross-linguistically, there are several options to realize case on predicative nouns and adjectives: case-concordance with the subject, default case (nominative), or lexically marked case (either structural or semantic). Consider the following examples from Finnish (Comrie 1997, Löbel 2000):

(i) Tiedän kirjan olevan valkoisen/valkoinen.

know.1sg book.GEN being white.GEN/white.NOM

'I know that the book is white'

(ii) Tiedän kirjojen olevan valkoiset/valkoisia.

know.1sg book.PL.GEN being white.PL.GEN/white.PL.PART

'I know that the books are white'

We, therefore, think that UNIQUENESS interacts with other constraints, one of these being CONCORD(case) ('Predicatives are realized with the same case as their subjects'). In this paper, however, we will not consider the case of predicatives.

${ }^{6}$ See Dixon (2000:48ff) for a typology of causativized transitive and ditransitive verbs, and Joppen (1999) for a more detailled study with a smaller sample of languages. That a semantic case can serve as last resort is obvious from agentive passives. Since passive prevents the agent from being structurally realized, the only way to express it is a semantic case (often the instrumental).
} 
the second option. The two constraints, MARK SEMANTICS and SEMANTIC COMPATIBILITY, are meant to capture such higher-ranked semantic circumstances (which, however, can vary from language to language in their special character). (2) illustrates the two scenarios for the linking of a medial argument of a ditransitive verb (the 'indirect object') if no dative is available.

(2) a. Type A: Structural case is the default, but may be overridden by semantic case (say, instrumental) in order to express a non-standard semantic constellation.

\begin{tabular}{|c|r|c|c|c|}
\cline { 2 - 5 } \multicolumn{2}{c|}{} & MARKSEM & STRUCTCASE & UNIQUENESS \\
\hline \multirow{2}{*}{ default } & ACC & & & $*$ \\
\cline { 2 - 5 } & INSTR & & $* !$ & \\
\hline \multirow{2}{*}{ non-default } & ACC & $* !$ & & $*$ \\
\cline { 2 - 5 } & INSTR & & $*$ & \\
\hline
\end{tabular}

b. Type B: Semantic case (say, instrumental) is the default, but may be overridden by structural case if the semantic case cannot be licensed by the meaning of the verb.

\begin{tabular}{|c|rr|c|c|}
\cline { 3 - 5 } \multicolumn{2}{c|}{} & SEMCOMP & UNIQUENESS & STRUCTCASE \\
\hline \multirow{2}{*}{ default } & ACC & & $* !$ & \\
\cline { 2 - 5 } & INSTR & & & $*$ \\
\hline non-default & ACC & & $*$ & $*$ \\
\cline { 2 - 5 } & INSTR & $* !$ & & $*$ \\
\hline
\end{tabular}

Both scenarios are standard in Optimality Theory: In a default situation the respective ranking of two constraints determines which alternative is chosen, but in a non-default situation these outputs may be reversed under the influence of still higher-ranked constraints.

The remainder of this paper proceeds as follows. In section 2 we present our framework for structural case, including a correspondence-theoretic account for the relation between abstract case and structural case, and furthermore show that semantic case is organized differently, although not in terms of the morphology. In section 3 we continue with a critical assessment of two similar claims made by Alsina (1992) for Chichewa and by Butt (1998) for Urdu. In section 4, we present a study on various Quechua dialects, which make different choices between structural and semantic case, depending on several semantic conditions. We will show that the two scenarios in (2) are realistic in that they successfully account for these choices. Our approach is also able to integrate other ways of structural linking, especially the positional linking of Chichewa (section 3.1) and the interaction between case and object agreement in Quechua (section 4.1). Since there are also dialects of Quechua in which semantic case coincides with object agreement, often taken as indicator for structural linking, we conclude that semantic case is not totally different from structural case. By contributing an additional semantic relation, semantic case can serve to avoid ambiguity. Thus, structural and semantic case are 'true' competitors. ${ }^{7}$

\footnotetext{
${ }^{7}$ Concerning the effects of morphological case, we think that the structural cases are generated by means of underlying abstract case features and do not have any effects apart from their function to disambiguate the possible participant readings of DPs, as required by UNIQUENESS. However, semantic case is mostly a free option and not generated by means of underlying features; it can therefore serve as the last resort to express a participant reading unequivocally.
} 


\section{The theoretical Framework: Lexical Decomposition Grammar}

\subsection{Abstract case features and structural case}

Lexical Decomposition Grammar (LDG; Joppen and Wunderlich 1995, Wunderlich 1997a,b, 2000, Kaufmann 1995, Kaufmann and Wunderlich 1998, Stiebels 1999, 2000) is a lexical theory aiming at a principled approach to argument structure and argument structure alternations. It is based on the idea that the Semantic Form (SF) of a lexical item is a partial semantic representation, including only those aspects of meaning that are relevant for the determination of argument roles, but rich enough to allow inferences to a more articulated Conceptual Structure (CS), a program that has first been set out by Bierwisch (1983), and Bierwisch and Lang (1987). More specifically, SF is often decomposed into more primitive predicates; it is formulated in a categorial language with binary branching in which each element is associated with a logical type. In a binary representation, the coordination ' $\&$ ' between semantic constituents must be asymmetric ([A [\& B]]); this captures the different roles of A and B in the realization of arguments, as well as in the conceptual structure.

The design characteristics of SF have already been discussed to some extent in the above-mentioned literature. Since they are not decisive for the topic of this paper, it suffices here to state that the SF of a lexical item (either basic or derived) determines the semantic ranking of arguments uniquely. This ranking is often visible from the default order of arguments. For instance, in a subordinate clause with a canonical ditransitive verb of German, the default order from left to right is Agent-Recipient-Theme, which is realized by the morphological cases nominative, dative, and accusative, respectively. Such a verb is represented by the formula in (3b): ${ }^{8}$
a. als der Mann dem Mädchen den Korb gab when the.NOM man the.DAT girl the.ACC basket gave 'when the man gave the girl the basket'

\section{b. 'give': $\quad \lambda \mathrm{z} \lambda \mathrm{y} \lambda \mathrm{x} \lambda \mathrm{s}\{\operatorname{ACT}(\mathrm{x}) \& \operatorname{BECOME} \operatorname{POSS}(\mathrm{y}, \mathrm{z})\}(\mathrm{s})$}

$\mathrm{ACT}$ is an unspecific action predicate specifying $\mathrm{x}$ as Agent, BECOME is a transition predicate in the sense of generative semantics (Dowty 1979), and POSS is a stative predicate specifying y as Recipient and $\mathrm{z}$ as Theme. However, according to the view of LDG, these semantic roles are not important for argument linking as a structural system. The variable s expresses the referential (situation) argument of the verb, which is visible for functional categories such as tense and aspect, as well as for adverbial modifiers, but not for the argument linking system (consequently, $\lambda$ s will be ignored in the following). The fact that $\operatorname{ACT}(\mathrm{x})$ and $\operatorname{BECOME} \operatorname{POSS}(\mathrm{y}, \mathrm{z})$ constitute certain subevents standing in a causal relation to each other is not expressed in (3), but can be inferred on the basis of our knowledge about event types (such as processes, transitions and states) and by means of more general constraints regulating the relation between SF and CS (Kaufmann 1995, Kaufmann and Wunderlich 1998).

The list of $\lambda$-abstractors in (3) is called Theta Structure (TS), which, according to the LDG architecture, functions as an interface level between SF and the morphological-syntactic structure

\footnotetext{
${ }^{8}$ This formula is short for the more explicit representation in (i):

(i) $[\lambda z[\lambda y[\lambda x[\lambda s[\{\operatorname{ACT}(x)[\&[\operatorname{BECOME}[[\operatorname{POSS}(\mathrm{z})](\mathrm{y})]]]\}(\mathrm{s})]]]]]$

One can verify from this representation that the argument ranking is $\mathrm{s}>\mathrm{x}>\mathrm{y}>\mathrm{z}$.. The expression in curly brackets is the 'propositional body' that predicates on s, the referential (situation) argument of the verb.
} 
MS: on the one hand, it reflects the semantic ranking of arguments in SF (with the lowest argument on the left and the highest argument on the right); on the other hand, it determines the realization of arguments. The organization of TS is thus fundamental for LDG's conception of argument structure. Following a proposal of Kiparsky (1992) in a modified version, the default ranking in TS is encoded by means of the features $[+\mathrm{hr}]$ 'there is a higher role', and [+lr] 'there is a lower role' ${ }^{9}$ The distribution of these features in TS characterizes the concept of abstract case. Moreover, the same features are used to specify the structural morphological cases (as well as agreement morphemes, pronominal affixes or clitics, and argument positions with respect to the verb or the finite auxiliary). With the structural cases in (4), the three canonical case patterns in (5) arise for an accusative or an ergative system with dative, respectively. ${ }^{10}$

\begin{tabular}{|c|c|c|c|c|c|}
\hline \multirow{5}{*}{$\begin{array}{l}\begin{array}{l}{[+\mathrm{hr},+\mathrm{lr}]} \\
{[+\mathrm{hr}]} \\
\end{array} \quad \text { a. }\end{array}$} & \multicolumn{2}{|l|}{ dative } & \multicolumn{3}{|c|}{ ergative } \\
\hline & ditransitives & & b. transi & ives & c. intransitive \\
\hline & $\lambda z \quad \lambda y$ & $\lambda x$ & $\lambda z$ & $\lambda x$ & $\lambda x$ \\
\hline & $+\mathrm{hr}$ & $-\mathrm{hr}$ & $+\mathrm{hr}$ & $-\mathrm{hr}$ & $-\mathrm{hr}$ \\
\hline & $+\mathrm{lr}$ & $+\operatorname{lr}$ & $-1 \mathrm{r}$ & $+\operatorname{lr}$ & $-1 \mathrm{r}$ \\
\hline ACC-system: & $\mathrm{ACC}$ & NOM & ACC & NOM & NOM \\
\hline ERG-syst & NOM & ERG & NOM & ERG & NOM \\
\hline
\end{tabular}

The actual argument realization of a verb may deviate from these canonical patterns in several respects:

(i) Some arguments in SF may be blocked from being structurally realized, for reasons inherent to SF - these arguments are not mapped to TS. ${ }^{11}$

(ii) An operation on TS such as passive (or antipassive) blocks the highest (or the lowest) argument from being structurally realized.

(iii) Some $\theta$-roles in SF can be marked by lexical features overriding the argument ranking in SF. For example, besides the canonical patterns, German also exhibits DAT-ACC-NOM, ACC-ACC-

\footnotetext{
${ }^{9}$ Kiparsky's features are [+HR] 'the highest role' $(=[-\mathrm{hr}]$ in LDG), and [+LR] 'the lowest role' $(=[-\mathrm{lr}]$ in LDG). The deviation from Kiparsky is motivated by markedness considerations: in Kiparsky's version, the most unmarked case, the nominative, realizes the role marked by $[+\mathrm{HR}]$ in an accusative system, and it realizes the role marked by $[+\mathrm{LR}]$ in an ergative system, which conflicts with the usual understanding of the role of morphological features. As Stiebels (2000) shows, Kiparsky's markedness theory even leads to wrong empirical predictions in the typology of argument linking.

${ }^{10}$ The marked morphological cases may bear additional semantic conditions concerning the kind of argument to be linked. As pointed out above, the Hindi accusative $-k o$ is only realized if the respective argument is human, specific animate, or definite inanimate (Mohanan 1994).

${ }^{11}$ For instance, in a resultative construction such as (i) it is not possible to express the substance that was drunk:

(i) Die Gäste tranken den Kühlschrank leer.

the guests drank the.ACC fridge empty

'The guests drank the fridge empty'

Such a 'shadow argument' (Pustejovsky 1995:63) cannot be mapped into the syntax because in the resultative SF it is shifted to a position where it no longer 1(exically)-commands the lowest argument (see the discussion in Wunderlich 1997a,b).
} 
NOM, GEN-DAT-NOM, DAT-NOM, GEN-NOM, NOM-DAT, ACC, and DAT (and even more case patterns can be found in Icelandic).

(iv) For some lexical items it is possible to add expletive or reflexive arguments in TS that do not

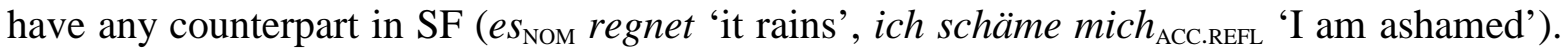
This strategy, however, always induces canonical patterns (thus, addition of expletive arguments and lexical marking of thematic arguments are complementary means).

If one interprets the abstract case features occurring in canonical transitives or ditransitives prototypically, the feature [+hr] correlates with proto-patient properties (the argument is affected by the event), and the feature [+lr] correlates with proto-agent properties (the argument controls the event) (Dowty 1991). ${ }^{12}$ The structural account to argument linking works independently from the question of whether a verb displays these proto-role properties or not. However, verb classes that deviate from the canonical pattern often do so for semantic reasons. If a lexical feature is assigned, thus overriding the default argument ranking, the feature [+hr] often invites the inference that the respective argument is affected, while [+lr] often invites the inference that the respective argument is a controller. (This does not exclude that some verbs have these features for purely idiosyncratic reasons.)

Two-place verbs that mark the highest argument with dative cross-linguistically represent Experiencer verbs, where an Experiencer could be defined as an argument that undergoes some affect without being the controller. In an accusative language like German, the lowest argument of a twoplace verb (such as helfen 'help', folgen 'follow') can be marked with dative; this argument often behaves as a controller himself. Since dative is decomposed into the feature combination [+hr, $+\mathrm{lr}]$, the lexical assignment of one of these features already warrants the appearence of the dative, provided that all other TS features are encoded by default. This is illustrated by the examples in (6) and (7). ${ }^{13}$

(6) Two-place Experiencer verbs with dative subject:

a. weil dem Lehrer der Roman gefiel

because the.DAT teacher the.NOM novel liked

'because the teacher liked the novel'

b.

$\begin{array}{llll} & \lambda y & \lambda x & \operatorname{LIKE}(\mathrm{x}, \mathrm{y}) \\ \text { lexical: } & & +\mathrm{hr} & \\ \text { default: } & +\mathrm{hr} & & \\ & -\mathrm{lr} & +\mathrm{lr} & \\ \text { case: } & \text { NOM } & \text { DAT } & \end{array}$

\footnotetext{
${ }^{12}$ There is also a correlation with aspect: a [+lr]-argument is relevant in the beginning of a situation (and consequently, is correlated with imperfect reading), while a [+hr]-argument is relevant at the end of a situation (and consequently, is correlated with perfect reading). Such a correlation with aspect is grammaticalized in the intransitive verbs of Yucatec, a Mayan language (Krämer and Wunderlich 1999).

${ }_{13}$ The question of why the lexical feature $[+\mathrm{hr}]$ in $(6 \mathrm{~b})$ induces inversion of the lowest argument to nominative is discussed in section 2.2.
} 
(7) Two-place verbs with dative object:

a. als Paul dem Studenten half / folgte

when Paul the.DAT student helped / followed

'when Paul the student helped/followed'

b.

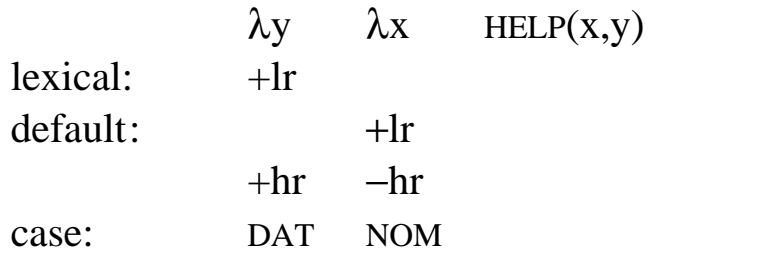

Another compelling example for lexical case assignment is given by the following minimal pair cited by Butt and King (1991) for Urdu. This language has a copula construction with ergative marking, translated by 'want', and another copula construction with accusative marking, translated by 'be obliged':
a. anjum-ne xat lik ${ }^{\mathrm{h}}$-naa hai.
Anjum-ERG letter-NOM write-INF is
'Anjum wants to write a letter'
b. anjum-ko xat lik ${ }^{\mathrm{h}}$-naa hai.
Anjum-ACC letter-NOM write-INF is
'Anjum has to write a letter'

Let us assume that the copula assigns the lexical feature [+lr] to the highest argument if it means 'want', while it assigns the feature [+hr] if it means 'be obliged'. This feature distribution is compatible with the inferences just discussed: someone who wants to do $\varphi$ must be in some control of $\varphi$, whereas someone who is obliged to do $\varphi$ is in a way affected for doing $\varphi$. We would not expect the reverse feature distribution. The two lexical entries of the copula expressing modal readings are given in (9):

$$
\begin{array}{llll}
\text { a. } & \lambda \mathrm{V} & \lambda \mathrm{x} \quad \text { WANT }(\mathrm{x}, \mathrm{V}(\mathrm{x})) \\
& \text { inf } & +\mathrm{lr} \\
& & (=\mathrm{ERG}) \\
\text { b. } & \lambda \mathrm{V} & \lambda \mathrm{x} \quad \text { OBLIG }(\mathrm{x}, \mathrm{V}(\mathrm{x})) \\
& \inf & +\mathrm{hr} & \\
& & (=\mathrm{ACC})
\end{array}
$$

In the next subsection we discuss the mechanism of structural argument linking in more detail, mainly with examples from German.

\subsection{The mapping between abstract and structural case ${ }^{14}$}

The relationship between abstract case, defined by [hr] and [lr] features on the theta structure, and morphological case, realized in the complements of the verb, can be seen as a correspondence-theoretic problem: all of the abstract case features (input), and only these, should be matched by the

\footnotetext{
${ }^{14}$ This section owes a lot to Stiebels (2000), who uses a similar apparatus for the typology of structural linking systems.
} 
morphological case features (output). This can be captured by faithfulness constraints belonging to the MAX or IDENT type. Moreover, each appearance of a morphological case feature in the output violates a markedness constraint.

(10) a. $\operatorname{MAX}(+\mathrm{F})$ : Every feature $[+\mathrm{F}]$ in the input has a correspondent in the output.

b. IDENT(F): Input-output correspondents should be identically specified for F.

c. $*[+\mathrm{F}]: \quad$ Avoid $[+\mathrm{F}]$ in the output.

An accusative system is determined by the ranking $\operatorname{MAX}(+\mathrm{hr})>*^{*}[+\mathrm{hr}]$, while an ergative system is determined by the ranking $\operatorname{MAX}(+1 \mathrm{lr}) \gg *[+1 \mathrm{l}]$. The respective reverse rankings prevent the emergence of accusative or ergative. Consider the optimal case pattern for transitive verbs in a pure accusative system, based on the default feature assignment in (11a).

(11) Canonical transitive verbs in an ACC-System

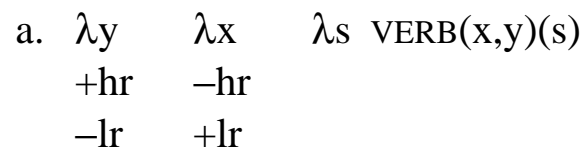

b. Evaluation of candidates:

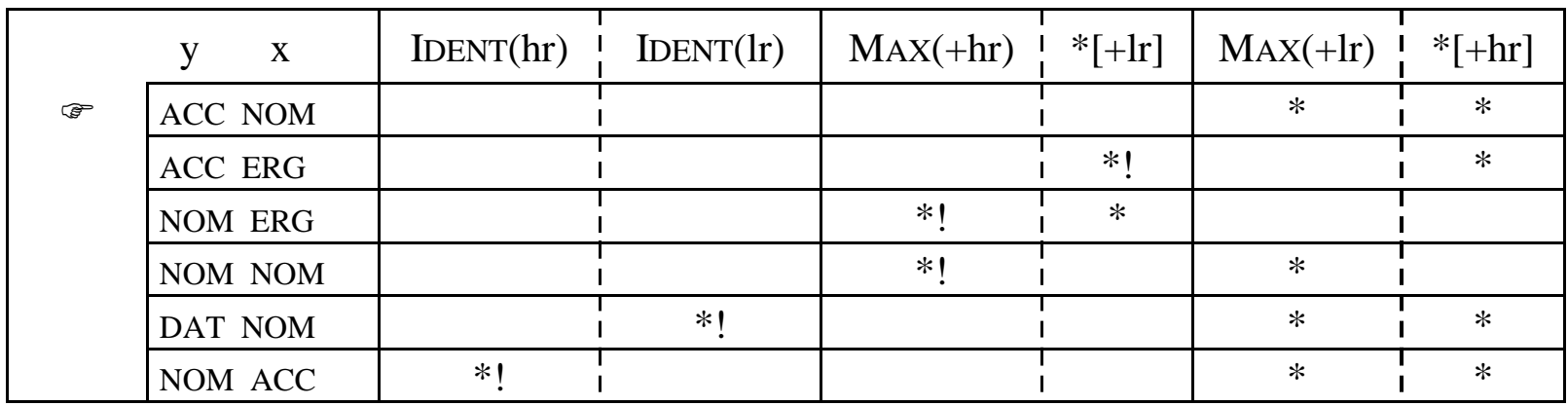

It is obvious that with the given constraint ranking, neither ergative nor dative can appear: ergative would violate $*[+1 \mathrm{lr}]$, and dative would violate IDENT(lr). Since IDENT constraints always rank highest, we omit them in the following. ${ }^{15}$

Additional constraints are necessary to account for the more complex case patterns in German. We think that the following constraints are intuitively justified. Lexically assigned features (overriding the default features) should be visible at the surface (12a). The default linker should occur in order to reduce markedness (12b), and UNIQUENESS should hold in order to avoid ambiguities (12b). A linking domain can be constituted by a single verb or by a verb complex (for instance, formed together with auxiliaries). Finally, underlying abstract case features should be made visible as far as possible. Since $*[+l r]$ ranks above $\operatorname{MAX}(+\operatorname{lr})$ in an accusative system, the occurrence of dative is rendered difficult; this situation can be overcome by a local constraint conjunction in the sense of Smolensky (1995), see (12d).

(12) a. MAX(lexF): A lexically assigned feature in the input has a correspondent in the output.

b. DEFAULT: Every linking domain must display the default linker (which is nominative).

c. UNIQUENESS: Each linker applies only once in a domain.

\footnotetext{
${ }^{15}$ Violation of IDENT would lead to case patterns from which the role of an argument cannot be detected anymore. Consider the last candidate in (11b), which reverses the case distribution of the optimal candidate.
} 
d. $\operatorname{Max}(+h r,+l r)$ : The feature combination $[+h r,+l r]$ in the input has a correspondent in the output.

These constraints are both necessary and sufficient in order to describe all of the case patterns found in German. We illustrate this first with three examples from ditransitive verbs in which a dative appears. Consider the active and the passive form of a canonical ditransitive verb.
a. als Peter dem Touristen
den Dom
zeigte
when Peter the.DAT tourist
the.ACC cathedra
showed
'when Peter showed the cathedral to the tourist'
b. als dem Touristen der Dom gezeigt wurde
when the.DAT tourist the.NOM cathedral shown was
'when the tourist was shown the cathedral'

As the data show, the dative is preserved in the passive, while the lowest argument is shifted to nominative. In the representation of passive, the highest (agentive) argument is assumed to be existentially bound, which, however, does not affect the specification of the theta structure in terms of [hr] and [lr], as shown in (14b).

$$
\begin{array}{lllll}
\text { a. Active: } & \lambda \mathrm{z} & \lambda \mathrm{y} & \lambda \mathrm{x} & \lambda \mathrm{s}\{\operatorname{ACT}(\mathrm{x}) \& \operatorname{SEE}(\mathrm{y}, \mathrm{z})\}(\mathrm{s}) \\
& +\mathrm{hr} & +\mathrm{hr} & -\mathrm{hr} & \\
& -\mathrm{lr} & +\mathrm{lr} & +\mathrm{lr} & \\
\text { b. Passive: } & \lambda \mathrm{z} & \lambda \mathrm{y} & \exists \mathrm{x} & \\
& +\mathrm{hr} & +\mathrm{hr} & & \\
& -\mathrm{lr} & +\mathrm{lr} & &
\end{array}
$$

\begin{tabular}{|c|c|c|c|c|c|c|c|c|c|c|c|}
\hline \multirow{6}{*}{ 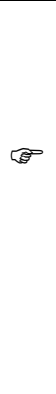 } & Z & $\mathrm{y}$ & $\mathrm{X}$ & $\begin{array}{l}\text { MAX } \\
(\operatorname{lexF})\end{array}$ & DEFAULT & $\begin{array}{c}\text { UNIQUE- } \\
\text { NESS }\end{array}$ & $\begin{array}{c}\text { MAX } \\
(+h r,+l r)\end{array}$ & $\begin{array}{l}\text { MAX } \\
(+h r)\end{array}$ & $*[+1 r]$ & $\begin{array}{l}\text { MAX } \\
(+1 r)\end{array}$ & $*[+\mathrm{hr}]$ \\
\hline & ACC & DAT & NOM & & & 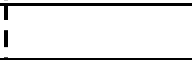 & & & $*$ & $*$ & $* *$ \\
\hline & $\mathrm{ACC}$ & $\mathrm{ACC}$ & $\mathrm{NOM}$ & & & $*$ & $*$ & & 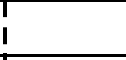 & $* *$ & $* *$ \\
\hline & $\mathrm{NOM}$ & ACC & $\mathrm{NOM}$ & & & $*$ & $*$ & $*$ & I & $* *$ & $*$ \\
\hline & $\mathrm{ACC}$ & $\mathrm{NOM}$ & NOM & & & $*$ & $*$ & $*$ & ? & $* *$ & $*$ \\
\hline & NOM & NOM & NOM & & & $* *$ & $*$ & $* *$ & I & $* *$ & 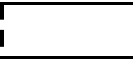 \\
\hline
\end{tabular}

The tableau (15) illustrates that either UNIQUENESS or MAX $(+\mathrm{hr},+\mathrm{lr})$ are necessary in order to establish the ACC-DAT-NOM pattern for the active of ditransitive verbs; otherwise the double accusative pattern of the second candidate would be optimal.

Ditransitive verbs in a DAT-ACC system

The case distribution in the passive of ditransitive verbs can be captured only if both DEFAULT and $\operatorname{MAX}(+\mathrm{hr},+\mathrm{lr})$ are assumed, as shown in tableau (16). 
(16) Passive of ditransitive verbs in a DAT-ACC system

\begin{tabular}{|c|c|c|c|c|c|c|c|c|c|c|}
\hline \multirow{6}{*}{$\circledast$} & Z & $\mathrm{y}$ & $\begin{array}{r}\text { MAX } \\
\text { (lexF) }\end{array}$ & DEFAULT & $\begin{array}{l}\text { UNIQUE- } \\
\text { NESS }\end{array}$ & $\begin{array}{c}\text { MAX } \\
(+h r,+l r)\end{array}$ & $\begin{array}{l}\text { MAX } \\
(+h r)\end{array}$ & $*[+1 \mathrm{lr}]$ & $\begin{array}{l}\text { MAX } \\
(+1 r)\end{array}$ & $*[+\mathrm{hr}]$ \\
\hline & $\mathrm{NOM}$ & DAT & & 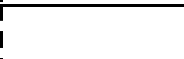 & $\begin{array}{l}i \\
i\end{array}$ & & $*$ & $*$ & & $*$ \\
\hline & ACC & DAT & & $* !$ & $\begin{array}{l}T \\
i\end{array}$ & & & * & & $* *$ \\
\hline & $\mathrm{ACC}$ & $\mathrm{ACC}$ & & $* !$ & $*$ & $*$ & & 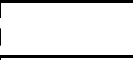 & $*$ & $* *$ \\
\hline & NOM & ACC & & 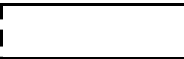 & I & $* !$ & $*$ & 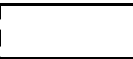 & $*$ & $*$ \\
\hline & NOM & NOM & & 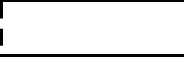 & $* !$ & $*$ & $* *$ & 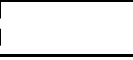 & $*$ & \\
\hline
\end{tabular}

In lexically marked ditransitives, the lowest argument is exceptionally marked for dative, while the medial argument is realized by accusative, as shown in (17).
weil
der Arzt den Patienten
einem Test unterzog
because the doctor the.ACC patient a.DAT test exposed
'because the doctor exposed the patient to a test'

We assume that the lowest $\theta$-role is lexically marked with the feature [+lr], which together with the default feature $[+\mathrm{hr}]$ allows the realization of dative. However, the medial argument is still marked as $[+\mathrm{hr},+\mathrm{lr}]$ by default.

$$
\begin{array}{lllll} 
& \lambda \mathrm{z} & \lambda \mathrm{y} & \lambda \mathrm{x} & \lambda \mathrm{s}\{\mathrm{ACT}(\mathrm{x}) \& \operatorname{BECOME} \operatorname{EXPOSED}(\mathrm{y}, \mathrm{z})\}(\mathrm{s}) \\
\text { lexical } & +\mathrm{lr} & & & \\
\text { default } & +\mathrm{hr} & +\mathrm{hr} & -\mathrm{hr} & \\
& & +\mathrm{lr} & +\mathrm{lr} &
\end{array}
$$

The following tableau shows that both MAX(lexF) and UNIQUENESS are necessary in order to estab-

\begin{tabular}{|c|c|c|c|c|c|c|c|c|c|c|c|}
\hline \multirow{5}{*}{ 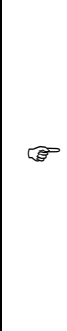 } & $\mathrm{Z}$ & $\mathrm{y}$ & $\mathrm{X}$ & $\begin{array}{l}\text { MAX } \\
(\text { lexF) }\end{array}$ & DEFAULT & $\begin{array}{l}\text { UNIQUE- } \\
\text { NESS }\end{array}$ & $\begin{array}{c}\text { MAX } \\
(+h r,+l r)\end{array}$ & $\begin{array}{l}\text { MAX } \\
(+h r)\end{array}$ & $*[+1 \mathrm{lr}]$ & $\begin{array}{l}\text { MAX } \\
(+1 r)\end{array}$ & $*[+\mathrm{hr}]$ \\
\hline & DAT & ACC & NOM & & I & & * & & $*$ & $* *$ & $* *$ \\
\hline & ACC & DAT & $\mathrm{NOM}$ & $* !$ & ? & & $*$ & & $*$ & $* *$ & $* *$ \\
\hline & DAT & DAT & NOM & & I & $* !$ & & & $* *$ & $*$ & $* *$ \\
\hline & ACC & ACC & NOM & $* !$ & T & $*$ & $* *$ & & & $* * *$ & $* *$ \\
\hline
\end{tabular}
lish the observed DAT-ACC-NOM pattern to be optimal. This evaluation furthermore shows that these two constraints must rank above MAX(+hr,+lr).

(19) Lexically marked ditransitive verbs in a DAT-ACC system

Summarizing so far, we have seen that the LDG linking mechanism is able to account for the German case system in terms of a small set of general constraints. A particular property of this account to structural case is that dative is decomposed into two features. The ranking of MAX $(+\mathrm{hr},+\mathrm{lr})$ above the individual constraints $\mathrm{MAX}(+\mathrm{hr})$ and $\mathrm{MAX}(+\mathrm{lr})$ thus automatically follows from the logic of constraint conjunction, while the ranking of MAX(dative) would not. Furthermore, the LDG account offers a principled solution to lexically marked cases. If the feature [+hr] is assigned to the highest argument of a 2-place verb, it leads to a NOM-DAT pattern (which is cross-linguistically characteristic for experiencer verbs), but if it is assigned to the single argument of an intransitive verb it leads 
to accusative, provided we assume that MAX(lexF) ranks above DeFAULT. These two instances of lexical marking are illustrated by the following examples.

(20) Dative subject experiencer verbs:

a. see example (6a) above

b. $\begin{array}{lll}\text { lexical: } & & +\mathrm{hr} \\ \text { default: } & +\mathrm{hr} & \\ & -\mathrm{lr} & +\mathrm{lr}\end{array}$

\begin{tabular}{|c|c|c|c|c|c|c|c|c|c|c|}
\hline c. & $\mathrm{y}$ & $\mathrm{X}$ & $\begin{array}{l}\text { MAX } \\
\text { (lexF) }\end{array}$ & DEFAULT & $\begin{array}{l}\text { UNIQUE- } \\
\text { NESS }\end{array}$ & $\begin{array}{c}\text { MAX } \\
(+\mathrm{hr},+\mathrm{lr})\end{array}$ & $\begin{array}{l}\text { MAX } \\
(+h r)\end{array}$ & $*[+l r]$ & $\begin{array}{l}\text { MAX } \\
(+1 r)\end{array}$ & $*[+\mathrm{hr}]$ \\
\hline \multirow[t]{2}{*}{$\leftrightarrow$} & NOM & DAT & & 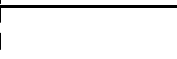 & i & & $*$ & $*$ & & $*$ \\
\hline & ACC & DAT & & $* !$ & $\begin{array}{l}T_{1} \\
i\end{array}$ & & & $*$ & & $* *$ \\
\hline
\end{tabular}

(21) Intransitive accusative verbs in German:

a. weil mich dürstet because 1sg.ACC thirsty 'because I am thirsty'

b. $\lambda \mathrm{x} \lambda \mathrm{s} \operatorname{ThiRSTy}(\mathrm{x})(\mathrm{s})$

lexical: $\quad+\mathrm{hr}$

default: $-1 \mathrm{r}$

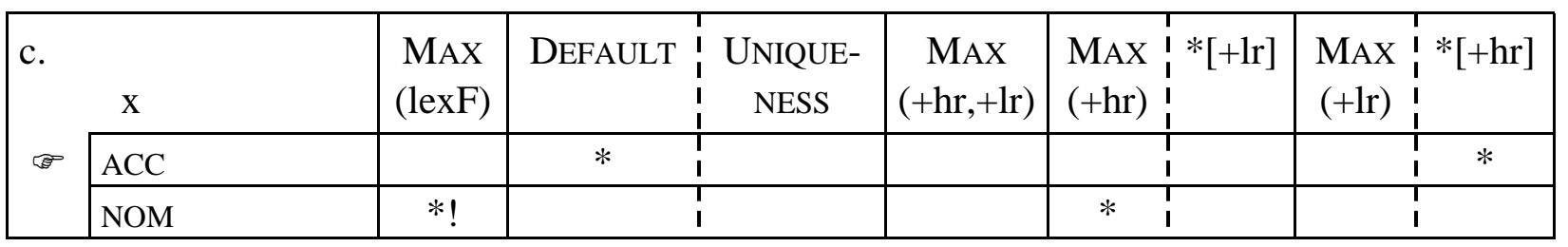

Another interesting fact about German is that double accusative verbs are very rare, which follows from the high ranking of UNIQUENESS. However, such a construction can be induced with the lexical feature $[-1 r]$ for the medial argument. Since a negative feature value is never visible in morphological case, only the highest-ranked constraint IDENT(lr) can explain the appearance of double accusative here. Thus, it seems that $\operatorname{IDENT}(\mathrm{F})$ and $\operatorname{MAx}(\mathrm{lexF})$ are somewhat similar in their function to preserve the abstract case configuration literally.

(22) Double accusative verbs in German:

a. als er mich den Reim lehrte when he 1sg.ACC the.ACC rhyme teached 'when he taught me the rhyme'

b. $\lambda \mathrm{z} \quad \lambda \mathrm{y} \quad \lambda \mathrm{x} \quad \lambda \mathrm{s}\{\operatorname{ACT}(\mathrm{x}) \& \operatorname{BECOME} \operatorname{KNOW}(\mathrm{y}, \mathrm{z})\}(\mathrm{s})$ $\begin{array}{llll}\text { lexical: } & & -\mathrm{lr} & \\ \text { default: } & +\mathrm{hr} & +\mathrm{hr} & -\mathrm{hr} \\ & -\mathrm{lr} & & +\mathrm{lr}\end{array}$ 


\begin{tabular}{|c|c|c|c|c|c|c|c|c|c|c|c|}
\hline c. & $\mathrm{Z}$ & $\mathrm{y}$ & $\mathrm{x}$ & $\begin{array}{c}\text { IDENT } \\
\text { (lr) }\end{array}$ & DEFAULT & $\begin{array}{c}\text { UNIQUE- } \\
\text { NESS }\end{array}$ & $\begin{array}{c}\text { MAX } \\
(+h r,+1 r)\end{array}$ & $\begin{array}{l}\text { MAX } \\
(+h r)\end{array}$ & $*[+\mathrm{lr}]$ & $\begin{array}{l}\text { MAX } \\
(+1 r)\end{array}$ & $*[+\mathrm{hr}]$ \\
\hline \multirow[t]{2}{*}{$\otimes$} & $\mathrm{ACC}$ & ACC & NOM & & & $*$ & & & 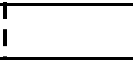 & $*$ & $* *$ \\
\hline & $\mathrm{ACC}$ & DAT & NOM & $* !$ & & & & & $*$ & $*$ & $* *$ \\
\hline
\end{tabular}

Thus, a rather simple system of constraint interaction, which makes reference to only two abstract case features, some general faithfulness and markedness constraints and four additional wellfounded constraints, is able to characterize the rather complex set of structural case patterns found in German. We will see, however, that the participation of semantic case requires different and more complex means.

\subsection{Semantic case}

Semantic case (such as instrumental, comitative, or directional) differs from structural case in that it encodes an additional relational predicate that must be licensed by the respective verb meaning. ${ }^{16}$ In this respect it is similar to a pre- or postposition. Semantic case (manifested by an affix or clitic) is, however, distinct from a pre-/postposition, which itself assigns structural case to its complement. Typically, semantic case occurs in adjuncts, but it can also occur in complements, if the verb is subcategorized for a semantic case by means of a morphological feature.

To illustrate the interaction between verb meaning and semantic case, let us first consider verbs of motion that take a directional PP (rather than a directional case) in German or English. Directional PPs occur as obligatory predicative arguments of causative position verbs (such as setzen 'set', stellen 'stand'); let us assume that they are optional arguments of motion verbs such as gehen 'go'. These verbs are then subcategorized for a PP by means of the feature [+loc,+dir]. Such a specification is met by the PP into the room, which adds the predicate 'become located in the interior of the room', as shown in (23a). If the relational predicate 'become located in the interior of' is already incorporated into the verb, as in enter, structural case appears instead, which is shown in (23b). Thus, semantic case in one verb may alternate with structural case in another verb, depending on how explicit the meaning of the verb is. ${ }^{17}$

a. in das Zimmer gehen 'go into the room'

gehen: $\quad \lambda \mathrm{P} \quad \lambda \mathrm{x}\{\mathrm{GO}(\mathrm{x}) \& \mathrm{P}(\mathrm{x})\}$

$[+$ loc, + dir $]$

in das Zimmer: [+dir]; $\lambda \mathrm{z}$ BECOME LOC(z, INT(the room))

b. das Zimmer betreten 'enter the room'

betreten: $\quad \lambda \mathrm{y} \lambda \mathrm{x}\{\mathrm{GO}(\mathrm{x}) \& \operatorname{BECOME} \operatorname{LOC}(\mathrm{x}, \mathrm{INT}(\mathrm{y}))\}$

\footnotetext{
${ }^{16}$ It is not important whether the semantic case encodes a single meaning or is ambiguous between several meanings (such as the Latin ablative, which marks, among others, origin, instrument, comparison, and measure). In the latter case, the selection of a particular case meaning also depends on the meaning of the verb (or the construction in which the verb appears). Mostly, however, one basic meaning can be assumed, whereas the other meanings only appear in specialized contexts.

${ }^{17}$ The German prefix be- is an applicative morpheme which adds a lower argument realizing a locative role.
} 
The interaction between verb meaning and locative case is slightly more complex in the FinnoUgric languages. Finnish distinguishes between the stative cases inessive and adessive ([+loc,-dir]), the goal cases illative and allative ([+loc,+dir,-source]), and the source cases elative and ablative ([+loc,+dir,+source]). In each pair of locative cases, the major distinction is whether something is located in the interior (or in direct contact) or in the exterior (including the surfacing regions). There are many verbs that require a locative case just from one of these pairs, depending on whether a location before or after the event is more relevant. This is illustrated by the examples in (24). ${ }^{18}$
a. Löys-i-n kirja-n laatiko-sta.
find-PAST-1 book-GEN box-ELA
'I found the book in [lit. from] the box'
b. Jät-i-n avaime-t auto-on.
leave-PAST-1 key-pl car-ILL
'I left the keys in [lit. into] the car'

What is relevant for a 'find' event is the place where something is located before the event, so the verb löytää 'find' requires a complement realized with either elative or ablative (similarly etsiä 'look for', ostaa 'buy', and lakata 'end'). By contrast, what is relevant for a (transitive) 'leave' event is the place where something is located after the event, so jättää 'leave' requires a complement realized with either illative or allative (similarly unohtaa 'forget', pysähtyä 'stop', jäädä 'stay', rakentaa 'build', ruveta 'begin', and all resultatives). ${ }^{19}$ The respective verbs are therefore subcategorized for a subclass of semantic cases.

a. Verbs subcategorized for elative/ablative:

$$
\begin{array}{cc}
\lambda \mathrm{P} & \lambda \mathrm{y} \lambda \mathrm{x} \lambda \mathrm{s}\{\operatorname{FIND}(\mathrm{x}, \mathrm{y})(\mathrm{s}) \& \mathrm{P}(\mathrm{y})(\mathrm{s})\} \\
{[+ \text { loc },+ \text { source }]}
\end{array}
$$

b. Verbs subcategorized for illative/allative:

$\lambda \mathrm{P} \quad \lambda \mathrm{y} \lambda \mathrm{x} \lambda \mathrm{s}\{\operatorname{FORGET}(\mathrm{x}, \mathrm{y})(\mathrm{s}) \& \mathrm{P}(\mathrm{y})(\mathrm{s})\}$

[+loc,-source]

That a semantic case must in addition be represented in terms of morphological features just like structural cases is also evidenced by case concord. In the Finnish DP or DemP, a morphological case (regardless of whether it is a structural or a semantic case) must be realized on every element of the phrase, unless it already bears a dependent case such as genitive. Consider the examples in (26), taken from Vainikka (1989).

\footnotetext{
${ }^{18}$ As Fong (1996) has shown, the directional cases are semantically weaker than a representation by means of BECOME would suggest: (24a) does not imply that the book has left the box, and (24b) does not imply that the keys were not located in the car before. The source cases only specify the location in the pre-state of the situation referred to by the verb, whereas the goal cases only specify the location in the post-state of the situation.

${ }^{19}$ The inclusion of lakata 'end' and ruveta 'begin' shows that the locative cases need not necessarily be spatially interpreted.
} 
(26)
a. [tuo-lla Virpi-n
nariseva-lla tuoli-lla $]_{\text {DemP }}$
(adessive)
that-ADE Virpi-GEN
squeaky-ADE chair-ADE
'on that squeaky chair of Virpi's'

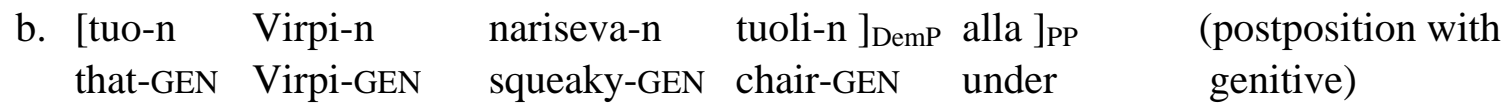
'under that squeaky chair of Virpi's'

In (26a), all elements of the demonstrative phrase except the genitive possessor are realized by adessive. This contrasts with a postposition such as alla 'under', which requires genitive for all elements of the DemP instead, as shown in (26b). Concerning its semantic contribution, the adessive is similar to a postposition, that is, the DemP in (26a) as a whole and not every occurrence of the adessive contributes the adessive meaning 'being located in the exterior/at the surface of'. In its formal aspects, however, semantic case is similar to structural case in that it can exhibit concord. ${ }^{20}$ The only difference is the interpretation of the relevant features: they reflect argument ranking in the structural cases, but express an additional semantic relation in the semantic cases.

In order to prepare the discussion in the following section, let us briefly consider another instance of semantic case, the instrumental in Hindi/Urdu. Although it appears in quite different contexts, it nevertheless has an invariant semantic meaning, according to the analysis by Mohanan (1994). Consider the examples in (27). The instrumental appears as a comitative adjunct in the active (27a), as an agentive adjunct in the passive (27b), and as a subject in a particular type of negative polarity construction $(27 \mathrm{c})$.
a. Anil-ne (Ravii-se) Raam-ko piitaa.
Anil-ERG (Ravi-INST) Ram-ACC beat.PERF
'Anil (together with Ravi) beat Ram'
b. Raam (Ravii-se) piitaa nahñ̃ gayaa.
Ram (Ravi-INST) beat.PERF not go.PERF
'Ram wasn't beaten (by Ravi)'
c. Ravii-se Raam-ko piitaa nahñ̃n gayaa.
Ravi-INST Ram-ACC beat.PERF not go.PERF
'Ravi couldn't (bring himself to) beat Ram'

\footnotetext{
${ }^{20}$ Another morphological phenomenon showing the formal similarity of structural and semantic case is casestacking in the Australian languages. Consider the following example from Martuthunira (Dench and Evans 1988:7):
(i) ngayu nhuwa-lalha tharnta-a kapuyu-marta-a thara-ngka-marta-a. 1sg.NOM spear-PAST euro-ACC little-PROP-ACC pouch-LOC-PROP-ACC

'I speared a Euro with a little one in its pouch'

The multiple occurrences of accusative and proprietive indicate the relevant domains of these cases. In order to derive the semantic representation, one has to find the (simplified) syntactic projection in (ii) and then account for the semantic values of the morphological features, thus arriving at the interpretation in (iii) for the accusative object.
}

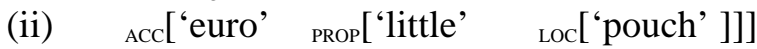

(iii) $\lambda \mathrm{x}[\operatorname{EuRO}(\mathrm{x}) \& \exists \mathrm{y}[\operatorname{POSS}(\mathrm{x}, \mathrm{y}) \& \operatorname{LiTTLE}(\mathrm{y}) \& \exists \mathrm{z}[\operatorname{LOC}(\mathrm{y}, \mathrm{z}) \& \operatorname{POUCH}(\mathrm{z})]]$ (See also the LFG analysis by Andrews 1996.) 
We assume that the instrumental case, morphologically marked as [+instr], contributes the information that the referent of the NP has control over the situation.

Ravii-se: $\lambda$ s CONTROLLED(s,Ravi)

All three readings of the instrumental in $(27 \mathrm{a}-\mathrm{c})$ can be derived from this control information. In the comitative reading of an active clause, the agent gets support from another actor who has at least partial control. In the passive (in which the agent is blocked from structural realization), the instrumental adjunct explicitly adds the controlling person. The instrumental subject construction, illustrated in (27c), is more complex. We assume that the auxiliaries ga and jaa ('go') function as negative polarity items selecting the perfect. If a nominative subject appears, the construction simply gets the reading 'couldn't do', but with an instrumental subject it gets the reading 'could not bring oneself to do' (Mohanan 1994:156), a reading that involves a person to decide whether or not he enters an action. This difference exactly follows from the information of the instrumental given in (28). Moreover, the instrumental subject is only possible with agentive verbs (such as muskuraa 'smile'), whereas with achievement verbs (such as gir 'fall', $g^{h}$ ar pahoc 'reach home'), which express a telic process independent of any control, the nominative is the only option.

The variation between instrumental and nominative as observed in the Hindi negative polarity construction with 'go' verbs thus nicely illustrates that semantic case is semantically richer than structural case, and hence must be compatible with the meaning of the verb, whereas the appearance of a structural case is determined solely by structural factors. This fact will be important in the following section.

\section{Semantic case and structural case competing with each other}

A language with dative allows to express all three arguments of a ditransitive verb by structural case; the medial argument is then canonically mapped to the dative. Only in (derived) 4-place verbs can the number of structural arguments exceed the number of distinct structural cases. As Joppen $(1999,2000)$ has shown with data from causativized ditransitive verbs, in these instances often one of the medial arguments is expressed by semantic case, in order to avoid a violation of UNIQUENESS (see also the survey in Dixon 2000:56 ff). In ergative languages such as Basque the recipient (the second-lowest argument) is preferrably semantically expressed (here, by means of the destinative), as illustrated in (29). Note that only the causee and not the recipient can be coindexed with the agreement pattern on the final auxiliary. By contrast, in accusative languages such as Turkish it is the causee (the second-highest argument) that is semantically expressed. Under certain circumstances, double dative is tolerated with causativized ditransitive verbs (30a), but never with double causatives (31a); furthermore, note that (31b) has only the reading with the recipient expressed.

(29) Basque (Joppen and Wunderlich 1995: 151)
a. Ni-k pobre-ei diru-a ema-ten diet.
1sg-ERG poor-pl.DAT money-DET.NOM give-IMPERF 3NOM.3plDAT.1ERG 'I am giving money to the poor'
b. 'Apeza-k ni-ri pobre-ei diru-a eman-araz-ten dit. priest-ERG 1sg-DAT poor-pl.DAT money-DET.NOM give-CAUS-PERF 3NOM.1DAT.3ERG
c. Apeza-k ni-ri pobre-entzat diru-a eman-araz-ten dit. priest-ERG 1sg-DAT poor-pl.DEST money-DET.NOM give-CAUS-PERF 3NOM.1DAT.3ERG 'The priest induced me to give money to the poor' 
(30) Turkish (Comrie 1985:340)
a. 'Disci
müdür-e
mektub-u
Hasan-a
göster-t-ti
dentist director-DAT letter-ACC
Hasan-DAT
show-CAUS-PAST
b. Disci
Hasan-a mektub-u
müdür tarafindan
göster-t-ti
dentist Hasan-DAT letter-ACC
director by
show-CAUS-PAST
'The dentist made the director show the letter to Hasan'

(31) Turkish (Zimmer 1976:411)
a. *Hasan-a mektub-u müdür-e ac-tir-t-ti-m.
Hasan-DAT letter-ACC director-DAT open-CAUS-CAUS-PAST-1sg
'I made Hasan make the director open the letter'
b. Müdür-e mektub-u ac-tir-t-tì-m.
director-DAT letter-ACC open-CAUS-CAUS-PAST-1sg
'I had someone make the director open the letter'
*'I had the director made someone open the letter'

These data already indicate that a semantic case on medial arguments appears as last resort (to avoid double dative) rather than being forced by a specific semantic need. Moreover, if we note that other ergative languages (such as Alutor) pattern with Basque, while other accusative languages (such as Japanese) pattern with Turkish, we are entitled to assume that the emergence of semantic case in polyadic verbs is at least to some extent structurally conditioned.

If a language exhibits only two structural cases, the number of structural arguments exceeds the number of distinct structural cases already in ditransitive verbs (both basic and derived). Two options are possible:
A Double objects realized by the same case are accepted.
B The medial argument is realized by semantic case.

From the discussion in the last section, one expects that the choice of option A or B depends on the type of verb. Structural case is always licensed, except when it is blocked by UNIQUENESS. Semantic case, by contrast, contributing a semantic predicate, is only licensed if the respective predicate is compatible with the meaning of the base verb. We will briefly consider examples from three typologically unrelated languages: Chichewa, Urdu, and Quechua.

3.1 Consider first the case of Chichewa, as studied by Alsina (1992). Chichewa marks the causee of transitive verbs either as a primary object or by the directional preposition $k w a$ (32a,b). The former is the only option for non-agentive verbs (33):
a. Nungu
i-na-phík-íts-a
kádzidzi maungu.
9.porcupine 9s-PAST-cook-CAUS-FV 1a.owl 6.pumpkins
'The porcupine made the owl cook the pumpkins'
b. Nungu i-na-phík-íts-a maungu (kwá kádzidzi ).
9.porcupine 9s-PAST-cook-CAUS-FV 6.pumpkins (to 1a.owl)
'The porcupine had the pumpkins cooked by the owl'
a. Chatsalira
a-ku-mv-éts-á
aná
phókoso.
1.Ch.
1SUBJ-PRES-hear-CAUS-FV
2.children
5.noise 
$\begin{array}{llll}\text { b. *Chatsalira } & \text { a-ku-mv-éts-á } & \text { phókoso } & \text { (kwa aná). } \\ \text { 1.Ch. } & \text { 1SUBJ-PRES-hear-CAUS-FV } & \text { 5.noise } & \text { (to 2.children) }\end{array}$

'Chatsalira is making the children hear the noise'

(32a) and (33a) are instances of the double-object construction: the primary object must be adjacent to the verb, can be expressed by means of an object marker, and can be the subject of the passive variant. All these properties cluster on the causee in (32a), while the object of 'cook' becomes secondary. In contrast, the object of 'cook' remains the primary object in (32b), and the causee is introduced by the directional preposition kwá.

Alsina (1992) analyzes the examples in (32) by the assumption that the causative morpheme requires an affected object to be realized as the primary object, which can either be the causee (32a) or the base object of the embedded agentive verb (32b). However, if the base object is unaffected, as in (33), only the causee can be realized as primary object. The position next to the verb (for the primary object) would thus encode additional semantic information ('affectedness'), which is in conflict with a structural account like the present one. In our view, the relevant semantic factor is control rather than affectedness: the directional PP is only adequate if the causee can decide about the action, that is, when it has control. We therefore propose the following alternative account: the causative morpheme adds a new highest argument (a causer), so that the causee becomes the second-highest. The selection of a directional PP for the causee must be licensed by an agentive base verb, otherwise semantic ranking decides: the highest object will be the primary object.

There is no indication that Chichewa uses the feature [lr] for argument ranking. Rather, the choice for the highest object can best be captured by means of the feature [ \pm ho] for 'there is (no) higher object', which is similar to the feature [ \pm hr] , except that it is reserved for [+hr]-roles.

\begin{tabular}{|c|c|c|c|c|}
\hline & $\lambda z$ & $\lambda y$ & $\lambda x$ & $\lambda \mathrm{s}\{\operatorname{ACT}(\mathrm{x}) \& \operatorname{COOK}(\mathrm{y}, \mathrm{z})\}(\mathrm{s})$ \\
\hline & $+\mathrm{hr}$ & $+\mathrm{hr}$ & $-\mathrm{hr}$ & \\
\hline & tho & -ho & & \\
\hline A. & SECO & PRIMO & SUBJ & $\begin{array}{l}\text { The double-object construction respects the semantic } \\
\text { hierarchy }\end{array}$ \\
\hline B. & PRIMO & DIR & SUBJ & $\begin{array}{l}\text { Semantic case is possible here if the causee has agent } \\
\text { properties }\end{array}$ \\
\hline
\end{tabular}

Chichewa has positional linking rather than structural case. The syntactic position next to the verb ( $\left[\mathrm{V} \_\right]$) is specified for [+hr] roles and the position that follows ( [ [V NP] _ ] ) is specified for [+ho] roles. We therefore have to adjust our terminology introduced at the beginning of this paper, see (1). The MAX-Constraints in (35a,b) make reference to positions, STRUCTURAL CASE is replaced by the more general constraint STRUCTURAL LINKER (35c), and UNIQUENESS more precisely refers to morphological distinctions (35d). Furthermore, we have to guarantee that a directional PP satisfing the causee role may not appear to the left of an NP argument, which is achieved by the alignment constraint in (35e). The fact that a directional PP is favored for agentive causees is expressed by MARK SEMANTICS, specified for the [+contr] feature (35f).
a. $\operatorname{MAX}(+h r)$
Realize an argument role with the feature [+hr] right-adjacent to the verb.
b. $\operatorname{MAX}(+\mathrm{ho}) \quad$ Realize an argument role with the feature [+ho] in the second position to the right of the verb. 
c. STRUCTLINKER Arguments are realized by structural linkers.

d. UNIQUENESS The arguments in a clause are morphologically distinct.

e. *Align(PP-NP) Avoid a PP to the left of an NP.

f. MARKSEM The feature $[+$ contr] for a $[+\mathrm{hr}]$ role is visible in the output.

With these constraints, the distribution of NP and PP arguments found in (32) and (33) can be predicted by assuming the constraint ranking in (36).

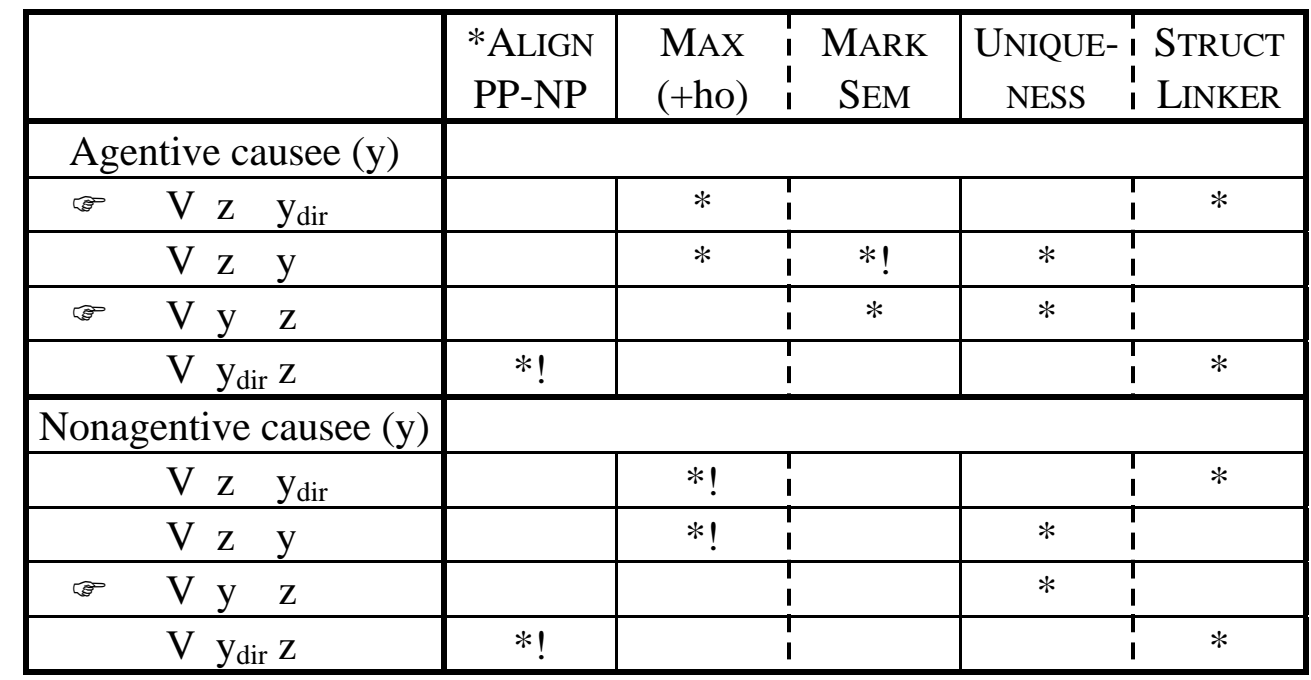

The first evalution accounts for the free variation between the double-object construction and the construction with a directional PP; this result arises because some of the constraints are not crucially ranked with respect to each other. However, if the verb does not have an agentive role that can be made explicit by a directional PP, only the double-object construction wins, as shown in the second evaluation. (MAX $(+h r)$ is irrelevant here because all candidates in (36) involve exactly one violation of this constraint.)

SEMANTIC COMPATIBILITY, the other semantic constraint assumed at the beginning of this paper, is also irrelevant here because the distribution of the directional PP is already captured by the other constraints. MARKSEM, however, is needed; if it is dropped from the tableau (36), there will be no longer two candidates that are equally good.

In the beginning of this paper we have considered two hypothetical scenarios, with STRUCTURAL CASE (LINKER) ranked above or below UNIQUENESS, respectively. Since these two constraints must be co-ranked in Chichewa in order to allow for free variation in one type of verbs, it is impossible to classify Chichewa as a type A or type B language. However, nothing in the hypothetical consideration excludes the pattern shown by Chichewa.

3.2 Urdu, studied by Butt (1998), behaves similarly to Chichewa, except that it has morphological case. Urdu marks the causee of transitive verbs either by accusative (-ko) or by instrumental case (-se). Some transitive verbs ('taste', 'read', 'write', and 'sing') allow for free variation between instrumental and accusative (37), but the majority of agentive transitive verbs takes instrumental case (38a). However, accusative is the only possibility for digestive ('eat', 'drink') and experiencer verbs ('learn', 'see') (38b). Recall that the Urdu accusative is restricted to human beings, specific animates or definite inanimates, so that the situation of double accusative does not occur in the given examples. 
(37)
a. anjum-ne saddaf-ko masaalaa
cak $^{\mathrm{h}}$-va-yaa.
Anjum.f-ERG Saddaf.f-ACC spice.m
taste -CAUS-PERF.msg
'Anjum had Saddaf taste the seasoning'
b. anjum-ne saddaf-se masaalaa
Anjum.f-ERG Saddaf.f-INST spice.m
cak $^{\mathrm{h}}$-va-yaa.
taste -CAUS-PERF.msg
'Anjum had the seasoning tasted by Saddaf'
a. anjum-ne saddaf-se/*k
paoda
kaat-a-yaa.
Anjum.f-ERG Saddaf.f-INST/ACC plant.m cut-CAUS-PERF.msg
'Anjum had Saddaf cut a/the plant'
b. anjum-ne saddaf-ko/*se $\mathrm{k}^{\mathrm{h}}$ aanaa $\mathrm{k}^{\mathrm{h}}$ il-a-yaa.
Anjum.f-ERG Saddaf.f-ACC/INST food.m eat-CAUS-PERF.msg
'Anjum gave Saddaf food to eat'

Butt argues that accusative causees are affected in the causal situation, while instrumental causees are not. She observes that examples with an affected causee must have a telic reading, whereas those with an unaffected causee allow for both a telic and an atelic reading. She accounts for this observation by claiming that an affected causee enters the relevant aspectual situation and therefore is linked to direct object; in contrast, the unaffected causee remains aspectually inert and is therefore linked to semantic case.

We have pointed out already that we doubt that a structural case can realize more semantic information than a semantic case, and therefore propose an alternative account. In (28) above, we have argued that the Urdu instrumental always adds a controller to the verb, that is, the instrumental in (37) and (38) requires the causee to be a potential controller. If a controller is present, the causal situation cannot be telic by itself because it is up to the controller whether and how the situation is bound. Agentive transitive verbs always require the causee to be a controller, so instrumental case is preferred. However, CONTROLLED is incompatible with experiencer verbs (and, for less obvious reasons, also with digestive verbs): here, accusative is the last resort. If a dependent controller is missing, causation implies telicity (namely that the result state is established). For a verb like 'taste' the controller property can be freely instantiated on the causee, so either option is possible.
a. $\lambda z \quad \lambda y^{+ \text {contr }}$
$+\mathrm{hr} \quad+\mathrm{hr} \quad+\mathrm{lr}$
+instr
$\lambda x \lambda s\{\operatorname{ACT}(x) \& \operatorname{CUT}(y, z)\}(s)$
b. $\lambda z \quad \lambda y^{- \text {contr }}$
$\lambda \mathrm{x} \lambda \mathrm{s}\{\operatorname{ACT}(\mathrm{x}) \& \operatorname{EAT}(\mathrm{y}, \mathrm{z})\}(\mathrm{s})$
$+\mathrm{hr} \quad+\mathrm{hr} \quad+\mathrm{lr}$
c. $\lambda z \quad \lambda y^{(+c o n t r)} \lambda x \lambda s\{\operatorname{ACT}(x) \& \operatorname{TASTE}(y, z)\}(s)$
$+\mathrm{hr} \quad+\mathrm{hr} \quad+\mathrm{lr}$
Instrumental case is obligatory
Instrumental case is incompatible
Both options are possible

The tableau in (40) shows that Urdu conforms to the type A scenario from the beginning of this paper: MAX (+contr) is a specific instance of MARKSEM, and MAX $(+\mathrm{hr})$ corresponds to STRUCTURAL CASE. 
(40)

\begin{tabular}{|c|c|c|c|}
\hline & MAX (+contr) & MAX (+hr) & UNIQUENESS \\
\hline $\begin{array}{r}\text { Agentive causee (y) } \\
\text { z y }\end{array}$ & \multicolumn{3}{|l|}{} \\
\hline acc instr & & $*$ & $*$ \\
\hline acc acc & $* !$ & & $*$ \\
\hline $\begin{array}{c}\text { Nonagentive causee (y) } \\
\mathrm{z} \quad \mathrm{y}\end{array}$ & & $* !$ & $*$ \\
\hline acc instr & & & $*$ \\
\hline acc acc & & & \\
\hline
\end{tabular}

3.3 Some Quechua dialects even allow for three ways of marking the causee, as shown by van de Kerke (1996) for the dialect of Tarata. (41) illustrates that the causee can be realized by directional case (marked with -man), by instrumental case (marked with -wan), or by accusative (marked with -ta); the examples have sligthly different readings.
a. warmi-y-ta aqha-ta llami-chi-saq.
woman-1sg-ACC chicha-ACC taste-CAUS-1sg.FUT
'I will have my wife taste the chicha' (coercive reading)
$\begin{array}{lll}\text { b. warmi-y-man } & \text { aqha-ta } & \text { llami-chi-saq. } \\ \text { woman-1sg-DIR } & \text { chicha-ACC } & \text { taste-CAUS-1sg.FUT }\end{array}$
'I will let my wife taste from the chicha' (recipient reading)
c. warmi-y-wan aqha-ta llami-chi-saq.
woman-1sg-INST chicha-ACC taste-CAUS-1sg.FUT
'I will make my wife taste the chicha' (comitative reading)

(vdKerke: 156)

This threefold marking clearly indicates that the choice between semantic case and structural case cannot be made on the basis of structural case adding semantic information (such as 'affectedness'), with semantic case being the default. Since there are two different semantic cases available, semantic case cannot be the default. The choice between semantic and structural case rather must be made on the basis of semantic case adding semantic information that is compatible with the meaning of the verb, otherwise the structural case appears. Instrumental case indicates that the causee performs the action by herself (although she may be forced a little), while directional case indicates that the causee is involved in the action as a recipient ('I already tried the chicha and now will share the glass with her'). With accusative, a coercive reading is the only possible one.

Like in Chichewa and Urdu, the choice of the respective case for the causee depends on the type of verb. Most experiencer verbs allow all three options, thus alternating between agentive and nonagentive readings, whereas other verbs are more restricted. With rikuy 'see' only the directional is possible, and with a canonical transitive verb like maylla 'wash' only the instrumental is possible.

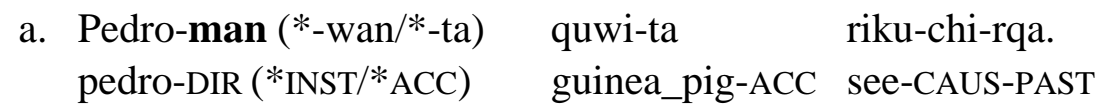

'(S)he showed Pedro the guinea-pig'

(vdKerke: 156)

b. Maria-wan $\left(*\right.$-man $/{ }^{*}$-ta) wawa-ta maylla-chi-n

Maria-INST $\left({ }^{*} \mathrm{DIR} / *^{*} \mathrm{ACC}\right)$ child-ACC wash-CAUS-n

'(S)he has the child washed by Maria'

(vdKerke: 108) 
This indicates that semantic case is generally preferred in the Tarata dialect. However, other Quechua dialects behave differently. In Huanca, for instance, double accusative is preferred:

$$
\begin{aligned}
& \text { Maria-kta wawi-kaq-ta alma-chi-lqa. } \\
& \text { Maria-ACC child-DEF-ACC wash-CAUS-PAST } \\
& \text { '(S)he had Maria wash the child' }
\end{aligned}
$$

We conclude that the various dialects of Quechua follow from different constraint rankings. UNIQUENESS ranks above STRUCTURAL CASE in those dialects in which semantic case is preferred (option B), such as Tarata, while the reverse order is found in dialects in which double accusative is preferred (option A), such as Huanca.

(44) a. Option A: Double accusative is preferred. (STRUCTURAL CASE >> UNIQUENESS)

b. Option B: Semantic case is preferred. (UnIQUENESS $>$ STRUCTURAL CASE)

In the next section, we will show that most dialects are consistent in their preferred choice in that they either follow option A or option B in both basic and derived ditransitive verbs. However, in each of these dialects, it is also possible to indicate non-standard semantic circumstances by the generally unpreferred choice. The dialect of Cuzco seems to constitute a transition stage because in this dialect basic ditransitives follow option B, while derived ditransitives follow option A. For independent reasons, dialects with option A are assumed to represent the historically earlier stages of Quechua (= Quechua I), and those with option B the historically later stages (= Quechua II); see Torero (1964). It may well be the case that the possibility to prefer semantic case first appears with basic verbs. The preferred choice of case linker also correlates with object agreement. In the dialects that take option A, semantic case and object agreement are mutually exclusive, while this is not the case in the dialects that take option B. In these dialects, object agreement and semantic case may coexist as linkers for one and the same argument. We conclude that the semantic cases have then acquired the status of structural-plus-semantic cases.

\section{A dialect variation in the competition between structural and semantic case}

\subsection{Quechua dialects following Option A}

The dialects of Ancash (spoken in the Department of Ancash, Peru) and Huanca (spoken in the southern provinces of the Department Junín, Peru) prefer double accusative, both in basic and derived ditransitives, if no ambiguity arises. These dialects belong to Quechua I, with the main characteristic feature that the plural morpheme immediately follows the verbal stem (whereas it follows the person agreement morphemes in Quechua II). These dialects represent the historically earlier stages of Quechua.

Under normal semantic conditions, structural case is preferred, both in basic ditransitives as in (45a) and in derived ditransitives as in (45b). (If not otherwise marked, all examples in this section are from Huanca, collected with the help of an informant.)
a. Wamla-kaq-ta yaku-kta qu-y. woman-DEF-ACC water-ACC give-IMP 'Give water to the woman!'
b. Wamla-kaq-ta yaku-kta apa-chi-lqa. woman- DEF-ACC water-ACC bring-CAUS-PAST 'She/he had the woman bring water'


However, under marked semantic circumstances, semantic case appears instead. First, semantic case is used to mark a source rather than a goal or recipient. (Note that in these dialects the directional -man is used for adjuncts only.)
a. yaqa-kta
illay-ta
maña-ma-lqa.
I-ACC
money-ACC borrow-1OBJ-PAST
'She/he has borrowed money to me'
b. yaqa-piqta illay-ta maña-ku-(*ma)-lqa.
I-SOURCE money-ACC borrow-REFL-(*1OBJ)-PAST
'She/he has borrowed money from me'

Second, semantic case is used to mark permissive rather than coercive causation. If we assume that -wan implies that the causee has control over the action by him/herself, the instrumental case can successfully indicate this difference. (We consider permissive causation to be semantically more complex than coercive causation, since it correlates with a higher degree of agency in the causee.)
a. allqu-ta maqa-tsi-rqa-yki wamra-ta.
dog-ACC beat-CAUS-PRET-2SG child-ACC
'You made the child beat the dog' (coercive)
b. allqu-ta maqa-tsi-rqa-yki wamra-wan.
dog-ACC beat-CAUS-PRET-2SG child-INSTR
'You let the child beat the dog' (permissive) (Ancash, Parker 1976: 121)

Third, semantic case is used to mark unexpected interpretations. Usually one does not expect that a person bites a dog, but in order to convey this constellation, the use of semantic case is necessary. (Literally, (47a) is ambiguous because it does not specify who is the one to be bitten.)
Wamla-kaq-wan allqu-kaq-ta kani-chi-lqa.
woman-DEF-INSTR dog-DEF-ACC bite-CAUS-PAST
'(S)he let the woman bite the dog'

Semantic case also serves to avoid other kinds of ambiguity. If only natural forces are involved in a situation, several causal chains may be possible. For instance, in a bad weather report with double accusative as in (49a), the affected object may be the banks of the river, or the trees along the river, or both. If one wants to express that more specifically, it is the floods of the river that damaged the trees, instrumental case is used as in $(49 \mathrm{~b})$.
a. Tamya-kaq mayu-kaq-ta rain-DEF river-DEF-ACC
hatun hatra-kuna-kaq-ta big tree-PL-DEF-ACC
aysa-chi-lqa.
'The rain caused the river and the big trees to get tored out' 'The rain let the river to tear out the big trees/ let the big trees to tear out the river'
b. Tamya-kaq mayu-kaq-wan hatun hatra-kuna-kaq-ta aysa-chi-lqa. rain-DEF river-DEF-INSTR big tree-PL-DEF-ACC tear.out-CAUS-PAST
'The rain let the river tear out the big trees'

Let us subsume all these possibilities under 'non-standard semantic circumstances'. The constraint MARK SEMANTICS, then, requires that such circumstances are overtly marked. Huanca thus conforms to the type A scenario (2a) from the beginning of the paper, repeated here as (50), with $\operatorname{Max}(+\mathrm{hr})$ as the requirement for structural case for the medial argument. 
(50)

\begin{tabular}{|c|r|c|c|c|}
\cline { 3 - 5 } \multicolumn{2}{c|}{} & MARKSEM & MAX $(+\mathrm{hr})$ & UNIQUENESS \\
\hline \multirow{2}{*}{ Default } & ACC & & & $*$ \\
\cline { 2 - 5 } & INSTR & & $* !$ & \\
\hline \multirow{2}{*}{ Non-default } & ACC & $* !$ & & $*$ \\
\cline { 2 - 5 } & INSTR & & $*$ & \\
\hline
\end{tabular}

Why is it always the medial argument that can receive semantic case for disambiguation, and never the lowest one? The medial argument can be associated with more semantic roles than the lowest argument, which is always the theme in ditransitive verbs. For instance, the type of causation is widely determined by the relation between the causer and the causee, and not by the relation between the causer and the theme. Furthermore, there is no semantic case available that is consistent with the theme role.

Let us now consider how the realization of morphological case interacts with agreement. All Quechua dialects have precisely two structural cases, the marked accusative and the unmarked nominative, and, besides subject agreement with all persons, they require object agreement with the 1st or 2nd person (except the Ecuadorian variety, which allows object agreement only with the 1st person). ${ }^{21}$ That is, the Quechua agreement system exhibits a rather common type of split: there are object markers for 1st and 2nd person, but not for 3rd person (see Stiebels 2000).

Moreover, if both objects are 1st or 2nd person, it is always the medial object (the causee) that is marked by object agreement. In this respect, Quechua behaves like other double-object languages. We therefore assume that the object roles are distinguished by the same feature [ho] as in Chichewa, introduced in section 3.1. Object agreement in Quechua can thus be described similar to object alignment in Chichewa: AGRO/1,2 requires object agreement with 1st and 2nd person, and *AGRSECO forbids object agreement with secondary objects, with the ranking AGRO/1,2 >> *AGRSECO. ${ }^{22}$

(51) a. AGRO/1,2: A [+hr] role is realized by agreement if it relates to 1 st or 2 nd person.

b. *AgRSECO: Avoid agreement with a [+ho] object role.

Considering the interaction of case and agreement, the several classes of verbs behave differently. Let us first consider causativized transitives, where the causee can potentially be realized by an instrumental. (52a) shows that double accusative appears if the causee is marked by agreement, while (52b) shows that the causee must receive semantic case if the lowest argument is marked by agreement.

a. (yaqa-kta) walmi-kaq-ta ñaqcha-chi-ma-n.

1sg-ACC woman-DEF-ACC comb-CAUS-1obj-3

'(s)he makes me comb the woman' (* '(s)he makes the woman comb me')

\footnotetext{
${ }^{21}$ The subject-object agreement paradigms in Quechua exhibit several anomalies, varying from dialect to dialect (Lakämper and Wunderlich 1998. Lakämper 2000), which, however, are not the topic of this paper. Here, we restrict ourselves to the regular instances.

${ }^{22}$ These constraints resemble MAX $(+h r)$ and $*[+h r]$ as used in section 2.2 for structural case. In order to avoid any confusion with case, we use the mnemonic terms in (51).
} 
b. walmi-wan (yaqa-kta) ñaqcha-chi-ma-n.

woman-INSTR 1sg-ACC comb-CAUS-1obj-3

'(s)he makes the woman comb me' (*'(s)he makes me comb the woman')

These examples reveal that only two out of the constellations listed in (53) are attested. Since either the causee or the theme can agree with the verb, it is the case distribution that disambiguates between these two readings.

(53) Possible and impossible linking constellations

\begin{tabular}{|c|c|c|c|c|c|c|c|c|c|}
\hline \multicolumn{4}{|c|}{ The causee $(\mathrm{y})$ is 1 st or 2 nd person } & \multicolumn{6}{|c|}{ The theme $(\mathrm{z})$ is 1 st or 2 nd person } \\
\hline \multicolumn{2}{|c|}{ a. possible } & \multicolumn{2}{|c|}{ b. impossible } & \multicolumn{3}{|c|}{ c. impossible } & \multicolumn{3}{|c|}{ d. possible } \\
\hline & $\begin{array}{cc}\lambda y & \lambda x \\
\text { agr } & \end{array}$ & & $\begin{array}{cc}\lambda y & \lambda x \\
\text { agr } & \end{array}$ & & & & $\begin{array}{c}\lambda z \\
\text { agr }\end{array}$ & & \\
\hline $\mathrm{ACC}$ & $\mathrm{ACC}$ & $\mathrm{ACC}$ & INSTR & $\mathrm{ACC}$ & $\mathrm{AC}$ & & $\mathrm{ACC}$ & INST & \\
\hline
\end{tabular}

It has been argued in the literature that candidate evaluation must be cyclic (Booij 1997, Kiparsky 1998). For the interaction of agreement and case, it is reasonable to assume that first agreement morphology is evaluated on the level of word structure, and then morphological case on the level of clause structure. This is especially justified if the language exhibits pro-drop, which Quechua does. Therefore, in order to account for the distribution shown in (53), we assume that agreement has been evaluated before case is selected. More precisely, we assume that semantic case is preferred if the secondary object is marked for agreement; thus the following constraint is a language-specific instance of MARK SEMANTICS, serving for disambiguation.

(54) MARKSEM/Agr: Realize [+hr,-ho] by semantic case if [+hr,+ho] is marked by agreement.

The ranking assumed in the tableaus (55) assures that only the constellations (53a) and (53d) can be chosen. If the causee is 1 st or 2 nd person, (53a) is optimal; if the lowest argument (the theme) is 1 st or 2 nd person, (53d) is optimal. (The letters a to $\mathrm{d}$ refer to the constellations in (53).)

a.

\begin{tabular}{|c|c|c|c|c|c|c|}
\hline & \multicolumn{3}{|c|}{ Case } & \multicolumn{2}{|c|}{ Agreement } \\
\hline & & $\begin{array}{c}\text { MARKSEM/ } \\
\text { AGR }\end{array}$ & $\begin{array}{l}\text { MAX } \\
(+h r)\end{array}$ & $\begin{array}{l}\text { UNIQUE- } \\
\text { NESS }\end{array}$ & $\begin{array}{c}\mathrm{AGRO} / \\
1,2\end{array}$ & $\begin{array}{l}* \text { AGR } \\
\text { SECO }\end{array}$ \\
\hline \multicolumn{7}{|c|}{$\begin{array}{l}\text { Causee (y) 1st or } 2 \text { nd pers. } \\
\qquad \mathrm{z}, \mathrm{y}\end{array}$} \\
\hline \multicolumn{7}{|c|}{$\$$ acc, agr+acc } \\
\hline \multicolumn{2}{|c|}{ acc, agr+instr } & & $* !$ & & & \\
\hline \multicolumn{2}{|r|}{ acc, acc } & & & $*$ & $* !$ & \\
\hline \multicolumn{2}{|r|}{ acc, instr } & & $*$ & & $* !$ & \\
\hline \multicolumn{7}{|c|}{ Theme $(\mathrm{z}) 1$ st or 2 nd pers. } \\
\hline \multicolumn{2}{|c|}{ agr+acc, acc } & $* !$ & & $*$ & & $*$ \\
\hline \multicolumn{2}{|c|}{ agr + acc, instr } & & $*$ & & & $*$ \\
\hline \multicolumn{2}{|c|}{ acc, $\quad$ acc } & & & $*$ & $* !$ & \\
\hline & acc, instr & & $*$ & & $* !$ & \\
\hline
\end{tabular}


A similar result can be found for the assistive, marked by -yshi. Like the causative, it introduces a new subject, so that the helpee becomes a medial argument, as shown in (56). In the double accusative construction the verb cannot agree with the base object, so that only the first reading is possible.

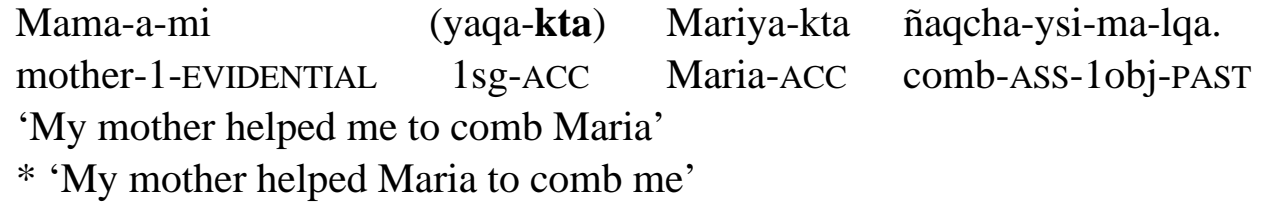

However, a different picture arises with basic ditransitive verbs. Here, only the double accusative pattern is found, as illustrated in (57).

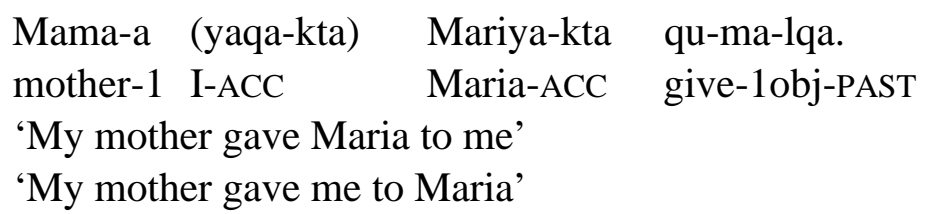

The two readings of (57) cannot be distinguished by means of semantic case in Huanca: instrumental case is inappropriate for a recipient, while directional case is only used for adjuncts. ${ }^{23}$ As a consequence, the constellation (53c) from above is possible here. We account for this fact by using the constraint SEMANTIC COMPATIBILITY, which checks whether a semantic case is licensed by the meaning of the verb. Candidate (58d), which was the optimal one in (55d), now violates this constraint because no semantic case is appropriate. Instead, the candidate in $(55 \mathrm{c})$ becomes optimal, even if it violates MARKSEM/AGR.

\begin{tabular}{|c|c|c|c|c||c|c|}
\hline $\begin{array}{c}\text { Theme }(\mathrm{z}) \text { 1st or 2nd person } \\
\mathrm{z}, \mathrm{y}\end{array}$ & $\begin{array}{c}\text { SEM } \\
\text { COMP }\end{array}$ & $\begin{array}{c}\text { MARKSEM/ } \\
\text { AGR }\end{array}$ & $\begin{array}{c}\text { MAX } \\
(+\mathrm{hr})\end{array}$ & $\begin{array}{c}\text { UNIQUE } \\
\text {-NESS }\end{array}$ & $\begin{array}{c}\text { AGRO/ } \\
1,2\end{array}$ & $\begin{array}{c}* \text { AGR } \\
\text { SECO }\end{array}$ \\
\hline agr+acc, acc & & $*$ & & $*$ & & $*$ \\
\hline agr+acc, instr/dir & $* !$ & & $*$ & & & $*$ \\
\hline
\end{tabular}

The reverse pattern (thus realizing a constellation similarly to (53b) above) is found with the benefactive. The benefactive suffix - $p u$ introduces a new argument, the beneficiary (which is either an intended recipient or a person in whose place the action is performed). Generally, the beneficiary takes preference with respect to agreement, as shown in (59). ${ }^{24}$

${ }^{23}$ Note that Quechua II dialects allow for directional case for the recipient. According to our informant, directional case is also possible for recipients in Ancash, another Quechua I dialect, where the two readings of the Huanca sentence (57) are distinguished as follows:
(i) Mama-a-mi
Maria-ta qu-ma-rqa-n.
mother-1POSS-EVIDENTIAL M.-ACC give-1obj-PAST-3
'My mother gave Maria to me'
(ii) Mama-a-mi Maria-man qu-ma-rqa-n.
mother-1POSS-EVIDENTIAL M.-DIR give-1obj-PAST-3
'My mother gave me to Maria'

However, speakers try to avoid the construction in (ii) and prefer a paraphrase with Maria maki-n-man '(gave me) to the hands of Maria'.

${ }^{24}$ (59a) cannot get the reading '(S)he gave me the book for you'. We are sure that, at least in the reading of an intended recipient, the beneficiary does not become the highest object with a ditransitive base verb. In 
(59)

$\begin{array}{llll}\text { a libru-kaq-ta } & \text { qam-ta } & \text { qu-pu-ma-lqa. } \\ \text { book-DEF-ACC } & \text { you-ACC } & \text { give-BEN-1OBJ-PAST }\end{array}$

'(S)he gave you the book for me'

b. (yaqa-paq) tanta-kta lanti-pu-ma-nki.

I-BEN bread-ACC buy-BEN-1OBJ-2

'You will buy bread for me'

Moreover, the beneficiary can only be expressed by semantic case. Therefore, it must be stated that semantic case and agreement can coincide under special circumstances. ${ }^{25} \mathrm{We}$ conceive of the requirement that beneficiaries be marked by semantic case as a subcase of MARK SEMANTICS.

\begin{tabular}{|c|c|c|c|c|c||c|c|}
\hline $\begin{array}{c}\text { Beneficiary 1st } \\
\text { or 2nd person } \\
\mathrm{z} \text { BEN }\end{array}$ & $\begin{array}{c}\text { SEM } \\
\text { COMP }\end{array}$ & $\begin{array}{c}\text { MARK } \\
\text { SEM (BEN) }\end{array}$ & $\begin{array}{c}\text { MARKSEM/ } \\
\text { AGR }\end{array}$ & $\begin{array}{c}\text { MAX } \\
(+\mathrm{hr})\end{array}$ & $\begin{array}{c}\text { UNIQUE- } \\
\text { NESS }\end{array}$ & $\begin{array}{c}\text { AGRO/ } \\
1,2\end{array}$ & $\begin{array}{c}* \text { AGR } \\
\text { SECO }^{26}\end{array}$ \\
\hline acc, agr+acc & & $* !$ & & & $*$ & & $(*)$ \\
\hline acc, agr+ben & & & & $*$ & & & $(*)$ \\
\hline
\end{tabular}

Having thus established the constraints that account for the case and agreement patterns we have observed for Huanca, we now turn to Tarata, the dialect investigated by van de Kerke (1996).

\subsection{Quechua dialects following option B}

The dialect of Tarata, located near the city of Cochabamba in central Bolivia, belongs to Quechua II and thus represents a historically later stage than Huanca and Ancash. As regards argument linking of ditransitive verbs, the main difference to the dialects discussed in the previous section is that UNIQUENESS is reranked, so that a violation of this constraint becomes more crucial. However, we will also discuss the alternative that structural-plus-semantic cases evolve, so that no reranking is necessary.

In Tarata, not only derived ditransitives (as illustrated in section 3.3 above), but also basic ditransitives prefer semantic case for the medial argument. Nevertheless, the verb can agree with this argument, as illustrated in (61a). The verb can furthermore even agree with a source argument, as in (61b).

$$
\begin{array}{lll}
\text { a. (ñuqa-man) } & \text { t'anta-ta } & \text { qu-wa-nqa } \\
\text { 1sg-DIR } & \text { bread-ACC } & \text { give-1obj-FUT } \\
\text { 'She/he will give me bread' }
\end{array}
$$

order to account for the fact that it nevertheless outranks the recipient of the base verb with respect to agreement we assume the following constraint:

(i) AGRNEWARG: A newly introduced argument takes preference in agreement.

This constraint is automatically respected in the causative and the assistive construction because the newly introduced argument (the causer or the helper) is realized as the subject.

${ }^{25}$ That semantic case and agreement can coincide may have enabled the further development in the dialects that take option $\mathrm{B}$, as indicated in section 4.2. According to the alternative we discuss there, we might say that the benefactive case of Huanca is already an instance of a structural-plus-semantic case, to be represented by [+hr,+ben]. It follows that the optimal candidate of (60) does no longer violate MAX(+hr).

${ }^{26}$ Whether this constraint is violated depends on whether the beneficiary happens to be the secondary object. In any instance, the selection of case remains the same. 

b. wawqi-y (ñuqa-manta) khuchu-na-ta maña-ku-wa-n. friend-1 I-SOURCE cut-NOML-ACC lend-REFL-1obj-3 'My friend borrows a knife from me' (vd Kerke: 107)

Semantic case is the default, but may be overridden by structural case if the semantic case cannot be licensed by the verb. This situation conforms to the type B, which we have hypothesized in the introduction and repeat slightly modified as (62):

\begin{tabular}{|c|rr|c|c|}
\cline { 3 - 5 } \multicolumn{2}{c|}{ Type B } & SEMCOMP & UNIQUENESS & MAX(+hr) \\
\hline default & ACC & & $* !$ & \\
\cline { 2 - 5 } & INSTR & & & $*$ \\
\hline \multirow{2}{*}{ non-default } & ACC & & $*$ & $*$ \\
\cline { 2 - 5 } & INSTR & $* !$ & & $*$ \\
\hline
\end{tabular}

Under normal semantic conditions, a semantic case is found (including the directional, which was a genuine adjunct case in Quechua I):
a. warmi wawa-y-wan chompa-ta awa-chi-saq. female child-1-INSTR sweater-ACC knit-CAUS-FUT 'I will let my daughter knit a sweater'
b. Pedro-man quwi-ta riku-chi-rqa.
Pedro-DIR guinea_pig-ACC see-CAUS-PRET
'She/he showed Pedro the guinea pig'

Instrumental with
agentive verbs

Directional with experiencer verbs

(vd Kerke: 156)

Structural case for the medial argument appears as last resort in this variety, namely if the situation to be expressed is incompatible with the information provided by a semantic case. This is illustrated with the coercive reading of causatives in (64a), and the assistive construction in (64b), where the helpee is incompatible with both the instrumental and the directional case. Structural case for the medial argument also appears if the lowest argument remains unexpressed, as in (65).

a. warmi-y-ta aqha-ta llami-chi-saq.

woman-1sg-ACC chicha-ACC taste-CAUS-1sg.FUT

'I will have my wife taste the chicha' (coercive)

(vd Kerke: 156)

b. mama-yki-ta p'acha-ta t'aqsa-ysi-na-yki tiya-n.

mother-2sg-ACC cloth-ACC wash-ASS-NOM-2sg be-3sg

'You should help your mother wash the clothes'

(vd Kerke: 153)

kurandero-ta hanpi-chi-ni.

medicine_man-ACC cure-CAUS-1

'I made the medicine man cure her/him'

(vd Kerke: 27)

As has been illustrated in (61), semantic case is compatible with agreement in the dialect of Tarata. Consequently, not only Structural CASE but also StrCASE/AgrO must be dominated by UNIQUENESS. The examples in (66) illustrate that in Tarata, the causativized verb 'wash' can agree with either object, while the medial argument is always realized by the instrumental. Thus, the linking constellation (53b), which is impossible in the Quechua I dialect of Huanca (except for benefactives), now is generally possible. For convenience, we repeat this constellation in (67). 
(66)

a. (ñoqa-wan) Maria-ta maylla-chi-wa-n.

I-INSTR Maria-acc wash-CAUS-1obj-3

'(S)he made me wash Maria'

b. Maria-wan (ñoqa-ta) maylla-chi-wa-n.

Maria-INSTR I-ACC wash-CAUS-1obj-3

'(S)he has me washed by Maria'

(vd Kerke: 109)

(67)

$\begin{array}{lll}\lambda z & \lambda y & \lambda x \\ & \text { agr } & \\ \text { ACC } & \text { INSTR }\end{array}$

The constraint ranking in (68) shows that this constellation is indeed optimal for Tarata.

(68)

\begin{tabular}{|c|c|c|c|c|c|c|}
\hline & $\begin{array}{l}\text { SEM } \\
\text { COMP } \\
\end{array}$ & $\begin{array}{l}\text { UNIQUE- } \\
\text { NESS }\end{array}$ & $\begin{array}{l}\text { MARKSEM/ } \\
\text { AGR }\end{array}$ & $\begin{array}{l}\text { MAX } \\
(+h r)\end{array}$ & $\begin{array}{c}\mathrm{AGRO} / \\
1,2 \\
\end{array}$ & $\begin{array}{l}* \text { AGR } \\
\text { SECO } \\
\end{array}$ \\
\hline \multicolumn{7}{|c|}{$\begin{array}{c}\text { Causee (y) 1st or 2nd ps. } \\
\text { z, y }\end{array}$} \\
\hline acc, agr+acc & & $* !$ & 1 & & & \\
\hline acc, agr+instr & & & 1 & $*$ & & \\
\hline acc, instr & & & 1 & $*$ & $* !$ & \\
\hline \multicolumn{7}{|c|}{$\begin{array}{c}\text { Theme (z) } 1 \text { st or } 2 \text { nd ps. } \\
\mathrm{z}, \quad \mathrm{y}\end{array}$} \\
\hline agr+acc, acc & & $* !$ & $*$ & & & * \\
\hline agr+acc, instr & & & T & $*$ & & $*$ \\
\hline acc, instr & & & 1 & $*$ & $* !$ & \\
\hline
\end{tabular}

The constraint ranking in (68) differs from that in (55) for Huanca only in the position of UNIQUENESS. Since there is independent evidence that Tarata represents a later stage of Quechua than Huanca, one has to conclude that UNIQUENESS has been up-ranked in the course of language change. However, for theoretical reasons (mainly concerning learnability) it is doubtful whether constraints can be up-ranked in language change. ${ }^{27}$

There is, however, an alternative conceivable explanation, namely that some of the semantic cases of Quechua II have acquired the status of structural cases, that is, represent structural-plussemantic cases: they satisfy the abstract case requirement, but, at the same time, explicitly add semantic information that is already implied by the meaning of the verb. Under this assumption, it is the lexical specification of the semantic case morphemes that has been changed, and not the constraint ranking. If the semantic cases are specified as [+hr, relational predicate], they never violate

\footnotetext{
${ }^{27}$ The 'constraint demotion' hypothesis for the learning of grammars (Tesar and Smolensky 1998) states that learners demote a constraint whenever they consider evidence for a violation of this constraint. This implies that a dialect shift only occurs if the younger population demotes a constraint farther than the elder population.
} 
MAX(+hr). Consequently, there is no need for UNIQUENESS to be up-ranked. The tableau (69) uses the same constraint ranking as (55), but different specifications for the instrumental case. ${ }^{28}$

(69)

\begin{tabular}{|c|c|c|c||c|c|}
\hline & $\begin{array}{c}\text { MARKSEM/ } \\
\text { AGR }\end{array}$ & $\begin{array}{c}\text { MAX } \\
(+\mathrm{hr})\end{array}$ & $\begin{array}{c}\text { UNIQUE- } \\
\text { NESS }\end{array}$ & $\begin{array}{c}\text { AGRO/ } \\
1,2\end{array}$ & $\begin{array}{c}\text { *AGR } \\
\text { SECO }\end{array}$ \\
\hline $\begin{array}{l}\text { Causee (y) 1st or 2nd pers. } \\
\mathrm{z}, \text { y }\end{array}$ & \multicolumn{5}{|l|}{} \\
\hline acc, agr+acc & & & $* !$ & & \\
\hline acc, agr+instr & & & & & \\
\hline acc, instr & & & & $* !$ & \\
\hline $\begin{array}{c}\text { Theme (z) 1st or 2nd pers. } \\
\text { z, y }\end{array}$ & \multicolumn{5}{|l||}{} \\
\hline agr+acc, acc & $* !$ & & $*$ & & $*$ \\
\hline agr+acc, instr & & & & & $*$ \\
\hline acc, instr & & & & $* !$ & \\
\hline
\end{tabular}

We have already encountered structural cases, such as Urdu/Hindi ergative and accusative, which are restricted by semantic conditions. Conversely, semantic cases such as Quechua instrumental and directional may have acquired properties of structural case. However, there is an important difference: semantically conditioned structural cases have to check semantic information (such as animacy, specificity, or control properties), whereas structural-plus-semantic cases explicitly add a semantic relation. Recall that instrumental and directional are often in free variation, leading to different readings (still competing with the accusative), which is something that we do not expect for semantically conditioned structural cases.

In order to decide between these two alternatives, constraint reranking or lexical specification of semantic case morphemes, it is useful to consider potential transition stages between Quechua I, as represented by Huanca, and Quechua II, as represented by Tarata.

\subsection{Transition stages}

Recall that the dialect of Huanca (Quechua I) prefers double accusative (option A) for all types of ditransitive verbs, while semantic case for the medial argument is found only under special semantic circumstances, moreover, semantic case is incompatible with object agreement (except for the benefactive). By contrast, the dialect of Tarata (Quechua II) prefers semantic case for the medial argument (option B), and here semantic case is compatible with object agreement. We will see that there are two different types of transition stages between these two systems, the first is represented by the dialect of Cuzco, and the second by the dialect of Potosí.

The dialect of Cuzco, located in southern Peru, takes option B with basic verbs, where the recipient is always marked by directional case, but option A with derived verbs, as illustrated in (70). Furthermore, all semantic cases are compatible with object agreement, see (71).

\footnotetext{
${ }^{28}$ Note that MARKSEM/AGR has become superfluous in both (68) and (69) because the respective candidates are already ruled out by UNIQUENESS. This indicates the special status of MARKSEM/AGR as a languagespecific instantiation in Quechua I dialects.
} 
(70)

a. Irqi-kuna-man musuq libro-ta amauta qu-rqa-n.

child-PL-DIR new book-ACC teacher give-PAST-3

'The teacher gave the children a new book'

$\begin{array}{llll}\text { b. Irqi-kuna-ta } & \text { amauta } & \text { qilqa-chi-rqa-n } & \text { harawi-ta. }^{29} \\ \text { child-pl-ACC } & \text { teacher } & \text { write-CAUS-PAST-3 } & \text { poem-ACC }\end{array}$

'The teacher made the children transcribe the poem'

(71) a ñuqa-man-qa qu-wa-n.

1sg-DIR-TOP give-1OBJ-3

'(s)he gave it to me' (Lefebvre and Muysken 1988: 81)

b. kay warmi ñuqa-manta qulqi-ta maña-ku-wa-ra-n.

this woman 1sg-SOURCE money-ACC borrow-REFL-1OBJ-PAST-3

'This woman borrowed money from me'

Thus, basic ditransitives behave similar to those in Tarata, while causativized transitives behave similar to those in Huanca. Since it is unreasonable to assume that the two patterns of ditransitive verbs follow from different constraint rankings, another explanation must be found. One could assume a unique constraint ranking that favors semantic case, but that, for some reason, the instrumental is restricted to more indirect readings. The latter assumption is not very plausible because the instrumental is generally available in the Quechua I dialects. More plausible is that the directional case (which is only used for adjuncts in Huanca, but see footnote 20) has adopted the potential to realize a 'true' argument of a verb, which, for semantic reasons, can only be a recipient and not a causee. Thus, the data in (70) can best be explained by the assumption that the directional (but not the instrumental) has acquired the status of a structural-plus-semantic case, to be represented by [+hr,+directional], where [+directional] must be licensed by the meaning of the verb.

This explanation suggests that option B (preferring semantic case) is a later innovation in Quechua. If we assume that it is first the basic ditransitive verbs that are construed under a new option, the transition from option A to option B takes place only after the basic ditransitives require directional case.

Geographically, Cuzco is located between the Quechua I dialects and the dialect of Tarata. One can, therefore, assume a dialect continuum that starts in the central Peruvian regions (where beneficiaries, introduced by the benefactive morpheme and realized by the benefactive case, are marked by agreement $[+h r]$ ), then stretches to the southern parts of Peru (where in addition, recipients in basic ditransitives, to be realized by directional case, are marked by agreement [+hr]), and finally reaches Bolivia (where also causees, potentially realized by instrumental case, are marked by agreement $[+h r])$.

Quite a different transition stage is represented by the Bolivian dialect of Potosí, which is located still more to the south than Tarata. The following data suggest that in this dialect, there is no crucial ordering between MAX(+hr) (=STRUCTURAL CASE) and UniQUENESS. According to our

\footnotetext{
${ }^{29}$ According to our informant, irqi-kuna-wan (child-PL-INSTR) would be possible but is unnecessarily complex because there can be no confusion with respect to the actual role of the participants. Furthermore, irqi-kuna-man (child-PL-DIR) is used by some speakers, but this happens under the influence of Spanish, where the directional preposition $a$ is used in such a case.
} 
informants, (72a) is only sligthly preferred over (72b), whereas (73b) is just as good as (73a). Note that the causee can also be expressed by instrumental case, which enables a more indirect reading.
a. Yacha-chi-q alumno-man
musuq libru-ta
qu-rqa. know-CAUS-NOML pupil-DIR new book-ACC give-PAST
'The teacher gave the pupil a new book'
b. Yacha-chi-q alumno-ta musuq libru-ta qu-rqa. know-CAUS-NOML pupil-ACC new book-ACC give-PAST
'The teacher gave the pupil a new book'
a. Yacha-chi-q
alumno-s-man poema-ta
copia-chi-rqa.
know-CAUS-NOML pupil-PL-DIR poem-ACC
'The teacher let the pupils copy the poem'
b. Yacha-chi-q alumno-s-ta poema-ta copia-chi-rqa.
know-CAUS-NOML pupil-PL-ACC poem-ACC copy-CAUS-PAST
'The teacher made the pupils copy the poem'

In Potosí, semantic case is compatible with object agreement, as illustrated by the following examples.
a. (ñuqa-man) qulqi-ta qu-wa-rqa-nki.
1sg-DIR money-ACC give-1OBJ-PAST-2
'you gave me money'
b. warmi-qa ñuqa-manta qulqi-ta maña-ku-wa-rqa.
woman-TOP 1sg-SOURCE money-ACC borrow-REFL-1OBJ-PAST
'The woman borrowed money from me'

Unlike Cuzco, Potosí does not make any important distinction between the type of verbs. It displays a system similar to that of Tarata, with the only difference that double accusative is just as good as the selection of semantic case. One can describe such a system by the assumption that the relevant constraints (UNIQUENESS and MAX $(+h r)$ ) are no longer crucially ranked with respect to each other, thus allowing for both options.

Let us assume that grammatical changes can occur in two ways: either some morphemes (such as the ones for semantic case) alter their lexical specification, or the constraint ranking is changed. The Cuzco data point to the former, and the Potosí data to the latter. Since geographically, Cuzco is located between the region where Huanca is spoken and the region of Tarata, whereas Potosí is even farther to the south than Tarata, the dialect of Cuzco is more likely to represent a transition stage than that of Potosí.

Our speculation, then, would be that Cuzco represents a transition stage (between Quechua I and the situation we observed in Tarata) whereas Potosí does not, for geographical as well as for systematic reasons. More precisely, we propose that the development of Quechua was triggered by the following innovations: first, only the benefactive was compatible with object agreement (Quechua I), then the directional case became compatible as well (Cuzco), and finally also the instrumental case (Tarata), without any relevant shift in the constraint order. Only after this stage became the 
system subject to reanalysis with respect to the constraint ranking (liberalizing the ranking of constraints), so that eventually the dialect of Potosí emerged. ${ }^{30}$

Our main findings about case realization for a medial argument are summarized in the following table:

(75) Preferred realizations of the medial argument:

\begin{tabular}{|l|c|c|c|c|}
\cline { 2 - 5 } \multicolumn{1}{c|}{} & Quechua I: & \multicolumn{3}{c|}{ Quechua II: } \\
\cline { 2 - 5 } \multicolumn{1}{c|}{} & $\begin{array}{c}\text { Ancash, Huanca } \\
\text { (Peru) }\end{array}$ & $\begin{array}{c}\text { Cuzco } \\
\text { (S. Peru) }\end{array}$ & $\begin{array}{c}\text { Tarata } \\
\text { (Bolivia) }\end{array}$ & $\begin{array}{c}\text { Potosí } \\
\text { (Bolivia, more } \\
\text { southern) }\end{array}$ \\
\hline 'give' & acc & dir & dir & acc/dir \\
\hline $\begin{array}{l}\text { causativized } \\
\text { transitives }\end{array}$ & acc & acc & dir/instr & acc/dir/instr \\
\hline & Type A & transition stage & (Type B) & 'liberalized' stage \\
\hline
\end{tabular}

\section{Conclusion}

We have argued that structural case solely depends on the semantic ranking of arguments, while semantic case is an exponent of additional semantic information. Therefore, semantic case is more informative than structural case. It is not excluded that a structural case (such as ergative or accusative) is also restricted to semantic conditions (such as animacy, specificity, or the capacity of being a controller). The alternative to a semantically conditioned structural case is a less marked structural case. We have furthermore argued that a lexically determined structural case (which overrides semantic ranking) may allow for the inference that the respective argument is a controller or that it is affected. However, both the notion of control and the notion of affectedness are superfluous (and even misleading) in all the core instances of structural case, where the appearance of structural case exclusively depends on the semantic ranking (which is a purely structural notion for semantic representations). Moreover, all structural case patterns, for example, those found in German, could be captured by the assumption of two abstract case features, [hr] and [lr], in a correspondence-theoretic account.

A different situation arises where ditransitive verbs call for two structural object cases but only one is available. In this situation a conflict arises, which we have described by the two constraints STRUCTURAL CASE (requiring that both objects are realized by structural case - which results, for example, in a double-accusative construction) and UNIQUENESS (requiring that the two objects are distinctively marked). We have considered several instances where either structural case or semantic case appears in such a situation. In all these instances, the alternative to structural case is more informative (rather than less informative), namely semantic case.

\footnotetext{
${ }^{30}$ Since we do not have any historical evidence we cannot exclude that the actual change proceeded differently from the scenario sketched. There could be several innovations originating from the same system (Quechua I) at different times. A change in the constraint ranking could have immediately led to the system represented by Potosí, whereas a later change in the lexical specification led to the systems we observed in Cuzco and Tarata.
} 
We therefore think that the claim made by Alsina and Butt, namely that situations of conflict are solved in that structural case is bound to semantic conditions (such as affectedness), is unmotivated. We have shown that situations of conflict are rather solved by preferring semantic case wherever it is compatible with the meaning of the verb. The variation between structural and semantic case found with individual verbs, as illustrated from Urdu and Quechua, is consistent with such an assumption.

Furthermore, we have studied how grammar reacts to such situations of conflict. We have proposed two possible scenarios, one in which STRUCTURAL CASE dominates UNIQUENESS, and another one in which the reverse holds. One major group of Quechua dialects (the Quechua I dialects) prefer the former ordering, while at least some dialects of the other major group (the Quechua II dialects) seem to prefer the latter.

Since Quechua marks agreement with 1st or 2nd person objects, we have also studied how the agreement facts influence the realization of case. In the Quechua I dialects, instrumental case is necessary for the medial argument if the lowest argument (exceptionally) agrees with the verb. Moreover, in the Quechua I dialects semantic case is incompatible with object agreement (with the exception of benefactives), while in the Quechua II dialects semantic case can coincide with object agreement. We have argued that in the latter situation, the semantic cases have adopted the feature [+hr] in order to realize the abstract case configuration of ditransitive verbs.

There is also some evidence for transitional stages within these two scenarios: in the dialect of Cuzco the lexical specification of semantic cases has changed, while in the dialect of Potosí the constraint ranking has changed.

Finally, we would like to point out that argument linking in which only structural cases compete with each other has less competitors, is more economic, more stable and less influenced by semantic factors than argument linking in which structural and semantic cases compete with each other. The few constraints that evaluate the mapping between abstract and structural case are well-founded by the concept of argument ranking, whereas the constraints that have to check semantic circumstances (such as MARK SEMANTICS and SEMANTIC COMPATIBILITY) are rather vague and need to be instantiated language-specificly on various grounds. This fact, then, corroborates our claim that structural case linking is more economic than semantic case linking, the latter being only a last resort for complex argument structures.

It is needless to say that much more work is necessary to substantiate our claims about constraint ranking in argument linking. However, we feel that we have contributed an interesting starting point to those investigations.

\section{References}

Alsina, Alex. 1992. On the argument structure of causatives. Linguistic Inquiry 23: 517-555.

Andrews, Avery. 1996. Semantic case-stacking and inside-out unification. Australian Journal of Linguistics 16: 1-55.

Bierwisch, Manfred. 1983. Semantische und konzeptuelle Repräsentation lexikalischer Einheiten. In: Rudolf Růžička and Wolfgang Motsch (eds.) Untersuchungen zur Semantik, 61-99. Berlin: Akademie Verlag. 
Bierwisch, Manfred. 1989. Thematische Rollen und Dekomposition. Seminar Papers. Third DGfS Summerschool, Hamburg.

Booij, Geert. 1997. Non-derivational phonology meets Lexical Phonology. In: Iggy Rocca (ed.) Derivations and constraints in phonology, 261-288. Oxford: Clerendon Press.

Butt, Miriam and Tracy King. 1991. Semantic case in Urdu. Papers from the 27th Regional Meeting of the Chicago Linguistics Society, 31-45.

Butt, Miriam. 1995. The Structure of Complex Predicates in Urdu. Stanford: CSLI.

Butt, Miriam. 1998. Constraining argument merger through aspect. In: Erhard Hinrichs et al. (eds.) Complex predicates in nonderivational syntax. (= Syntax and Semantics 30), 73-113. San Diego: Academic Press.

Comrie, Bernard. 1985. Causative verb formation and other verb-deriving morphology. In: Tim Shopen (ed.) Language typology and syntactic description. Vol. III, Grammatical categories and the lexicon, 309-348. Cambridge University Press.

Comrie, Bernard. 1997. The typology of predicate case marking. In: J. Bybee, J. Haiman and S. A. Thompson (eds.) Essays on language function and language type, 39-50. Amsterdam: Benjamins.

Dench, Alan and Nicholas Evans. 1988. Multiple case-marking in Australian languages. Australian Journal of Linguistics 8: 1-48.

Dixon, R. M. W. 2000. A typology of causatives. In: R.M.W. Dixon and Alexandra Y. Aikhenvald (eds.) Changing valency. Case studies in transitivity, 30-83. Cambridge University Press.

Dowty, David. 1979. Word meaning and Montague Grammar. Dordrecht: Reidel.

Dowty, David. 1991. Thematic proto-roles and argument selection. Language 67: 547-619.

Fong, Vivienne. 1996. A temporal interpretation for locative case. Proceed. 15th WCCFL.

Joppen, Sandra. 1999. Structural arguments with semantic case: The case of causees and recipients in 4-place verbs. In: D. Wunderlich (ed.) Papers on Argument Linking. Working papers SFB Theorie des Lexikons, No. 112: 1-33, University of Düsseldorf.

Joppen, Sandra. 2000. Verbklassen und Argumentlinking. Nicht-kanonische Argumente, Expletiva und vierstellige Kausativa in Ergativ- versus Akkusativsprachen. Phil. Diss. University of Düsseldorf.

Joppen, Sandra and Dieter Wunderlich. 1995. Argument linking in Basque. Lingua 97: 123-169.

Kaufmann, Ingrid. 1995. What is an (im-)possible verb? Restrictions on Semantic Form and their consequences for argument structure. Folia Linguistica 29: 67-103.

Kaufmann, Ingrid and Dieter Wunderlich. 1998. Cross-linguistic patterns of resultatives. Working papers SFB Theorie des Lexikons, No. 109, University of Düsseldorf.

Kiparsky, Paul. 1992. Structural case. Ms, Institute for Advanced Study, Berlin.

Kiparsky, Paul. 1998. Paradigm effects and opacity. Ms, Stanford University.

Krämer, Martin and Dieter Wunderlich. 1999. Transitivity alternations in Yucatec, and the correlation between aspect and argument roles. Linguistics 37: 431-479. 
Lakämper, Renate. 2000. Plural- und Objektmarkierung in Quechua. Phil. Diss. University of Düsseldorf

Lakämper, Renate and Dieter Wunderlich. 1998. Person marking in Quechua - a constraint-based minimalist analysis. Lingua 105: 113-148.

Lefebvre, Claire and Pieter Muysken. 1988. Mixed categories. Nominalizations in Quechua. Dordrecht: Kluwer.

Löbel. Elisabeth. 2000. Case alternation in Finnish copular construction. In: B. Stiebels and D. Wunderlich (eds.) Lexicon in focus, 145-173. Berlin: Akadamie Verlag. In print.

Mohanan, Tara. 1994. Argument structure in Hindi. Stanford: CSLI.

Parker, Gary. 1976. Gramática quechua: Ancash-Huailas. Lima, Peru: Ministerio de Educación, Instituto de Estudios Peruanos.

Pustejovsky, James. 1995. The generative lexicon. Cambridge (Mass.): MIT Press.

Smolensky, Paul. 1995. On the internal structure of the constraint component Con of UG. Paper presented at UCLA.

Stiebels, Barbara. 1999. Noun-verb symmetries in Nahuatl nominalizations. Natural Language and Linguistic Theory 17: 783-836.

Stiebels, Barbara. 2000. Linker inventories, linking splits and lexical economy. In: B. Stiebels and D. Wunderlich (eds.) Lexicon in focus, 213-247. Berlin: Akademie Verlag. In print.

Tesar, Bruce and Paul Smolensky. 1998. Learnability in Optimality Theory. Linguistic Inquiry 29: 229-268.

Torero, Alfredo. 1964. Los dialectos quechuas. Anales científicas de la Universidad Agraria 2: 446478. Lima, Peru.

Vainikka, Anne. 1989. Deriving syntactic representations in Finnish. Doctoral dissertation, Univ. of Massachusetts, Amherst.

van de Kerke, Simon. 1996. Affix order and interpretation in Bolivian Quechua. Doctoral dissertation, Univ. of Amsterdam.

Wunderlich, Dieter. 1994. Towards a lexicon-based theory of agreement. Theoretical Linguistics 20: $1-35$.

Wunderlich, Dieter. 1997a. Cause and the structure of verbs. Linguistic Inquiry 28: 27-68.

Wunderlich, Dieter. 1997b. Argument extension by lexical adjunction. Journal of Semantics 14: 95142.

Wunderlich, Dieter. 2000. Predicate composition and argument extension as general options - a study in the interface of semantic and conceptual structure. In: B. Stiebels and D. Wunderlich (eds.) Lexicon in focus, 249-272. Berlin: Akademie Verlag. In print.

Zimmer, Karl. 1976. Some constraints on Turkish causativization. In: Masayoshi Shibatani (ed.) The grammar of causative constructions (= Syntax and Semantics 6), 399-412. New York: Academic Press. 